NBER WORKING PAPER SERIES

\title{
EARLY EFFECTS OF THE 2010 AFFORDABLE CARE ACT MEDICAID EXPANSIONS ON FEDERAL DISABILITY PROGRAM PARTICIPATION
}

\author{
Pinka Chatterji \\ Yue Li \\ Working Paper 22531 \\ http://www.nber.org/papers/w22531 \\ NATIONAL BUREAU OF ECONOMIC RESEARCH \\ 1050 Massachusetts Avenue \\ Cambridge, MA 02138 \\ August 2016
}

The authors thank participants at the 2016 ASHEcon meeting, particularly our discussant Ben Cook, for helpful comments. The authors also thank seminar participants at the 2016 University at Albany Health Economics Summer Work Group for helpful comments and feedback The views expressed herein are those of the authors and do not necessarily reflect the views of the National Bureau of Economic Research.

NBER working papers are circulated for discussion and comment purposes. They have not been peer-reviewed or been subject to the review by the NBER Board of Directors that accompanies official NBER publications.

(C) 2016 by Pinka Chatterji and Yue Li. All rights reserved. Short sections of text, not to exceed two paragraphs, may be quoted without explicit permission provided that full credit, including () notice, is given to the source. 
Early Effects of the 2010 Affordable Care Act Medicaid Expansions on Federal Disability

Program Participation

Pinka Chatterji and Yue Li

NBER Working Paper No. 22531

August 2016

JEL No. I10,I13

\title{
ABSTRACT
}

We test whether early Affordable Care Act (ACA) Medicaid expansions in Connecticut (CT), Minnesota (MN), California (CA), and the District of Columbia (DC) affected SSI applications, SSI and DI awards, and the number of SSI and DI beneficiaries. We use a difference-indifference (DD) approach, comparing SSI/DI outcomes pre and post each early Medicaid expansion ("Early Expanders") to SSI/DI outcomes in states that expanded Medicaid in January 2014 ("Later Expanders"). We also use a synthetic control approach, in which we examine SSI/ DI outcomes before and after the Medicaid expansion in each Early Expander state, utilizing a weighted combination of Later Expanders as a comparison group. In CT, the Medicaid expansion is associated a statistically significant, 7 percent reduction in SSI beneficiaries; this finding is consistent across the DD and synthetic control methods. For DC, MN and CA, we do not find consistent evidence that the Medicaid expansions affected disability-related outcomes.

\author{
Pinka Chatterji \\ State University of New York at Albany \\ Economics Department \\ 1400 Washington Avenue \\ Albany, NY 12222 \\ and NBER \\ pchatterji@albany.edu \\ Yue Li \\ Department of Economics \\ 1400 Washington Avenue \\ Albany, NY 12222 \\ USA \\ yli49@albany.edu
}




\section{Introduction}

The United States has an employment-based health insurance system for the working-age population, and this system has both advantages and disadvantages for people with disabilities (Gruber, 2000). The main advantage is the pooling of risks, as employers have the potential to bring together large groups of people for reasons unrelated to their health status. This pooling of risks reduces adverse selection and spreads administrative costs over large groups, lowering the price of insurance (Gruber \& Madrian, 1993). This is important for individuals with disabilities who are employed and have access to employer-sponsored health insurance. One disadvantage of an employment-based system, however, is that individuals with disabilities who cannot work full-time may not have access to private health insurance through an employer. These individuals also are likely to face cost-related barriers and, until recently, were likely to encounter waiting periods and preexisting conditions exclusions in purchasing private insurance directly from an insurance company. Even when affordable private insurance plans are available, these plans typically have not covered all the services that disabled individuals need, such as therapy and long-term care (The Arc, 2012; Peele et al., 2002). For these reasons, some disabled individuals may turn to the federal disability programs -- Supplemental Security Income (SSI) and Social Security Disability Insurance (DI) - not just for the income support these programs provide but also because these programs are linked to public health insurance eligibility.

The 2010 Patient Protection and Affordable Care Act (ACA) addressed some of the structural barriers that disabled individuals face in obtaining insurance coverage. In the private insurance market, the ACA built on prior state and federal reforms by eliminating insurance waiting periods and denials of coverage for preexisting conditions; banning annual and lifetime dollar limits on benefits; and making it illegal for insurance companies to rescind insurance coverage when a beneficiary becomes ill (Kaiser Family Foundation, 2012). The ACA's Health Insurance Marketplaces also are expected to offer more affordable and comprehensive private coverage options for people with disabilities compared to what was available previously (The Arc, 2012). 
In the public health insurance market, the ACA was intended to broaden Medicaid eligibility to include all adults with incomes below 138\% of the Federal Poverty Level (FPL) by January 2014. Although this policy was not targeted at disabled adults specifically, it may have opened an important new avenue to accessing public insurance among low-income, childless, disabled adults, most of whom previously had no access to public health insurance programs other than through SSI and DI. This is particularly true in states that previously had Medicaid programs with low income-eligibility thresholds, and Medicaid programs that did not cover any childless adults (Kennedy \& Blodgett, 2014). In previous Medicaid expansions that targeted low-income, childless adults, the newly covered beneficiaries tended to resemble the SSI population in the sense that they had high levels of health needs, including high rates of behavioral health disorders (Somers et al., 2010). Thus, it is likely that the ACA's recent Medicaid expansions, while not specifically targeted at individuals with disabilities, will tend to attract a large number of new beneficiaries who have debilitating and chronic health conditions.

If Medicaid expansions open up a new pathway to public insurance for disabled adults, then these expansions may be expected to reduce SSI and DI caseloads, if obtaining public insurance was a primary motivation for some individuals to apply for disability benefits. Similarly, if Medicaid expansions improve health among disabled adults, these individuals may be more likely to be able to continue working and stay off or exit the federal disability programs. On the other hand, Medicaid expansions may reduce insurance-motivated employment lock, encouraging some currently employed workers to leave their jobs and apply for disability assistance, since they now potentially could be covered by Medicaid until their eligibility for public insurance through the disability programs becomes effective (this waiting period is discussed further in the next section). Also, if low-income people with high levels of health need tend to migrate to or avoid moving away from states that expanded Medicaid, this increase in the low-income, relatively unhealthy population is likely to induce an increase in the numbers of both SSI and DI recipients. Because of these potentially counter-veiling effects, the net effect of Medicaid expansions on receipt of federal disability benefits remains an empirical question. 
In this paper, we test whether the early Medicaid expansions in Connecticut (CT), Minnesota (MN), California (CA), and the District of Columbia (DC) have affected SSI applications, SSI and DI awards, and the number of SSI and DI beneficiaries. We begin by using a difference-in-difference (DD) approach, comparing SSI/DI outcomes pre and post the early Medicaid expansions in CT, MN, CA and DC (“Early Expanders”) to SSI/DI outcomes in states that expanded Medicaid later, in January 2014 (“Later Expanders”). We also use DD methods to examine the hypothesized mechanisms linking Medicaid expansions to SSI/DI outcomes - insurance status, health, population growth, and net migration of childless, low-income individuals. We find, however, that the critical assumption of parallel trends in the pre-policy period, which underlies the DD method, is not reasonable for some outcomes. Thus, we move to a synthetic control approach, in which we examine SSI/DI outcomes before and after the ACA Medicaid expansion in each Early Expander state, utilizing a weighted combination of Later Expander states as a comparison group.

In CT, we find that the Medicaid expansion is associated with a statistically significant, 7 percent reduction in the percent of the population receiving SSI benefits; this finding is consistent across the DD and synthetic control methods. The DD model findings also indicate that CT's Medicaid expansion reduced SSI awards, and reduced DI awards and recipients, but these effects are no longer statistically significant when we apply the synthetic control approach. For CA and MN, although our DD model results suggest that the Medicaid expansion reduced some SSI/DI-related outcomes, the synthetic control findings show little evidence that the early Medicaid expansions are associated with disability applications, awards, or recipients. Finally, in DC, the DD models suggest the Medicaid expansion increased SSI awards and recipients, but these findings do not persist in the synthetic control estimates.

The DD models indicate that the Medicaid expansion was associated with increased net migration of low-income, childless adults into CT and DC, but only in the year the expansion went into effect. Overall, then, aside from the Medicaid expansion in CT which appears to have reduced the 
number of SSI beneficiaries, this study does not support the idea that early Medicaid expansions affected the propensity of the targeted individuals to apply for, enter, or leave the federal disability programs.

\section{Background}

Medicaid is a joint federal and state-funded public health insurance program that, until recently, primarily covered low-income children, parents, and elderly people, as well as some disabled and blind individuals. The ACA provided federal funding for states to expand Medicaid to adults with incomes below 138 percent of the FPL (Bitler \& Zavodny, 2014). As of March 2016, 31 states and DC have adopted the ACA expansion of Medicaid, while the remaining states have not yet done so (Kaiser Family Foundation, 2016). As the ACA's Medicaid expansions unfold in many states across the U.S., millions of low-income adults are gaining eligibility for public health insurance for the first time. This major health policy change is likely to have implications for health insurance coverage, labor market outcomes, health outcomes, and financial outcomes among low-income people, and recent studies have started to document these effects (Hu et al., 2016; Kaestner et al, 2016; Frean et al., 2016; Somers et al. 2010, 2013, 2014, 2016).

The ACA Medicaid expansions, however, also may have important effects on the number of people applying for and receiving benefits from the federal disability programs, SSI and DI. Before the ACA was passed, one main route through which low-income, disabled adults could access public health insurance was through the SSI and DI programs. ${ }^{1}$ The SSI program provides cash benefits for individuals who are low-income and have a work-limiting disability. The program is funded through general tax revenues, and only people with disabilities as well as low-income and low assets are eligible (Social Security Administration, 2006). In 32 states and DC, SSI eligibility confers Medicaid eligibility;

\footnotetext{
${ }^{1}$ There are other ways in which disabled adults potentially can access Medicaid including: (1) the State Supplemental Program (SSP), which augments the SSI program in most states (potentially covering some disabled individuals whose incomes are too high to be eligible for SSI) and may be linked to Medicaid; (2) state Medicaid programs for the disabled low-income and for the medically needy populations; (3) state buy-in programs for disabled individuals. See Wagner (2014) for more details.
} 
the two programs share the same application, and Medicaid eligibility starts in the same month as SSI eligibility. In 7 other states, the SSI and Medicaid programs have the same eligibility criteria, but have separate application processes. ${ }^{2}$ In the remaining 11 states, the Medicaid eligibility rules and application process differ from that of the SSI program (Social Security Administration, 2016a). ${ }^{3}$

The DI program provides cash benefits and access to Medicare, after a 2 year waiting period, for disabled individuals with adequate work history. The program is funded through payroll taxes. Benefits are based on the worker's earnings history and may be paid to workers and their dependents. The 2 year waiting period for Medicare begins on the date the individual becomes eligible for DI benefits. In some states, however, individuals waiting for Medicare coverage through the DI program can participate in states’ Medicaid buy-in and Medicaid medically needy programs (McInerney, 2013). In short, applying for and becoming eligible for SSI and DI provides access to public health insurance coverage for many individuals. This linkage may be especially important for SSI, since SSI is linked to Medicaid, and Medicaid tends to provide comprehensive coverage with little cost-sharing.

There are several possible mechanisms through which Medicaid expansions may affect federal disability caseloads. First, Medicaid expansions may reduce both SSI and DI caseloads if accessing public health insurance is a primary motivation for many existing and potential federal disability beneficiaries. The expansion of Medicaid to low-income, childless adults weakens the linkage between federal disability programs and public health insurance, at least for some disabled individuals who may choose to continue working and not apply for disability benefits if they can access Medicaid without doing so. Second, Medicaid expansions may reduce both SSI and DI caseloads if the expansions improve health, allowing for disabled individuals to continue working. For example, in the Oregon Medicaid Experiment, access to Medicaid was associated with improvements in mental health

\footnotetext{
2 These states are AK, ID, KS, NE, NV, OR, and UT.

${ }^{3}$ These states are CT, HI, IL, IN, MN, MO, NH, ND, OH, OK, and VA. CT and MN are two of the states we study in this paper. In CT and MN, the Medicaid income and asset limitations are different than those of the SSI program. See http://www.nolo.com/legal-encyclopedia/connecticut-disability-benefits-social-security-filinginsurance-options.html and http://www.nolo.com/legal-encyclopedia/minnesota-disability-benefits-socialsecurity-filing-insurance-options.html.
} 
(Finkelstein et al. 2012); if these types of effects on health are substantial, they could lead to reductions in federal disability caseloads.

On the other hand, the Medicaid expansions may reduce “employment lock” or the tendency for individuals to stay in jobs that would leave otherwise in order to maintain employer-sponsored health insurance coverage. Through this route, Medicaid expansions may increase participation in DI due to its potential to cover DI applicants during the two-year waiting period in which they no longer have employer-sponsored health insurance (ESHI) but do not yet qualify for Medicare (Gruber \& Kubik, 2002). Although there is no such waiting period to obtain Medicaid through SSI, applicants still must wait until their disability determination is successfully completed to obtain Medicaid through SSI. In this way, Medicaid expansions similarly may induce higher rates of SSI applications and caseloads.

Finally, Medicaid expansions may affect migration decisions. If a state’s Medicaid expansion attracts new migrants to the state, or reduces out-migration from the state, there is likely to be an increase in SSI/DI caseloads. Schwatrz \& Sommers (2014) test whether there was in-migration associated with the Medicaid expansions that took place in Arizona and New York in 2001 and in Maine in 2002, and health care reform in Massachusetts in 2006-2007. They find no evidence that these policy changes were associated with migration among low-income adults.

In general, although there are large literatures examining the effects of prior Medicaid expansions and policy changes, as well as many studies focusing on the effects of policies related to the federal disability programs, there are only a few recent studies that focus specifically on how expansions in access to Medicaid affect federal disability program participation. Maestas et al. (2014) test whether the 2006 state health care reform in Massachusetts, which reduced un-insurance rates in the state by 48 percent, affected participation in federal disability programs. They use a difference-in-difference (DD) study design, comparing the change in the rate of federal disability applications before and after the policy change in Massachusetts to this same change before and after the policy change in other Northeast states. Notably, these authors can examine heterogeneous effects by county. They find that in 
counties with relatively high insurance coverage rates, state health care reform in MA was associated with an increase in federal disability applications, supporting the idea that Medicaid expansions reduced “employment lock” in populations likely to have employer-sponsored health insurance coverage. In counties with relatively low insurance coverage rates, however, the MA health care reform was associated with a decline in federal disability applications, suggesting that at least some individuals in low-insurance counties were seeking disability benefits primarily to obtain Medicaid coverage.

In a recent working paper, Burns \& Dague (2016) use DD methods to test whether state Medicaid expansions targeting low-income, childless adults between 2001 and 2013 are associated with SSI participation. This paper is notable in that it draws on comprehensive data regarding these expansions, including information on enrollment caps and waiting lists. The classification of states’ Medicaid expansions, however, is somewhat different from our paper. Burns \& Dague (2016) consider an expansion in CA that took place in 2007, while we examine the expansion in CA that took place in 2011. Also, they consider the DC and MN to be in the comparison group, while we examine recent Medicaid expansions that took place in these states in 2010 and 2011. Burns \& Dague (2016) report that on average Medicaid expansions for childless adults are associated with a 7 percent reduction in SSI participation among childless adults. This finding supports the idea that some federal disability beneficiaries seek benefits primarily because those benefits are linked to Medicaid.

We build on these two recent studies by testing whether recent Medicaid expansions under the ACA are associated with federal disability caseloads and associated mechanisms. We focus on estimating the effects of some of the earliest Medicaid expansions on outcomes. Five states -- CT, New Jersey (NJ), MN, Washington (WA), CA -- and DC expanded their Medicaid programs early, in 2010 and 2011. In all of these states, the early ACA Medicaid expansions replaced or enhanced state or local health insurance programs that already had existed for low-income adults (Sommers, 2013); nearly 950,000 individuals enrolled in Medicaid between the time of these early expansions and January 1, 2014 (Kaiser Family Foundation, 2015). In CT, MN, CA and DC, there is evidence that these early 
expansions resulted in a substantial increase in the number of individuals receiving public insurance (Sommers et al., 2014; Sommers et al. 2015), while in NJ and WA, the effect of expansion on public insurance coverage was limited by more restrictive eligibility requirements and/or lower take-up rates (Somers et al., 2013). Thus, we focus on early Medicaid expansions in these four states - CT, MN, CA and DC - in this paper. The recent expansions that we study are somewhat different than those studied by Burns \& Dague, in that the ACA early expansions were built on previous state-run programs, transferring large numbers of beneficiaries from state-run programs to Medicaid, and there were improvements over the previously state-run programs, such as more comprehensive coverage and expanded provider networks (Somers et al., 2013).

Table 1 summarizes the details of the Medicaid expansions in the four states we study. The expansions took place in 2010 for DC and CT, and in 2011 for MN and CA. All four of these early expansions were based on pre-existing state insurance programs for low-income people, but there was considerable heterogeneity across the expansions; for this reason, it makes sense to examine each state’s expansion separately. In DC, the expansion included the population up to $200 \%$ of the FPL, while in CT and $\mathrm{MN}$, the income thresholds for eligibility were $56 \%$ and $75 \%$ of the FPL, respectively (Somers et al., 2012). In CA, a new program called the Low Income Health Plan was created for low-income adults up to $200 \%$ of the FPL. Individual counties in CA, however, could choose whether or not to participate in the Medicaid expansion, and participating counties could choose their own income thresholds. Between July 2011 and March 2013, 52 of the 58 counties in CA chose to expand Medicaid (Golberstein et al., 2015). Sommers et al. (2014), using difference-in-difference methods with neighboring states as the comparison groups, finds that the early Medicaid expansions are associated with increases in Medicaid enrollments in CT and DC in the targeted low-income populations, particularly among childless adults with health limitations. Similarly, Somers et al. (2016), using difference-in-difference methods with counties that did not expand Medicaid as the comparison group, find that the CA Medicaid expansion was associated with an increase in Medicaid coverage. We build on these studies 
by examining effects on a different set of outcomes - federal disability outcomes - and by using synthetic control methods, which perform better than difference-in-difference methods in our case.

\section{Methods}

Following most previous research, we start with a difference-in-difference (DD) approach to estimate the effects of early Medicaid expansions on federal disability outcomes. We consider the treatment group to be each of the four states that expanded Medicaid early (CT, MN, DC and CA "Early Expanders”) and the comparison group to be the fifteen states that expanded Medicaid on January 1, 2014 (“Later Expanders”). ${ }^{4}$ The general specification is shown in Equation 1. In Equation 1, the dependent variable, $\mathrm{y}_{\mathrm{st}}$, is a federal disability outcome measured in state $\mathrm{s}$ in year $\mathrm{t}$ (e.g., percent receiving SSI benefits). The independent variables include: an indicator of whether the state expanded Medicaid early (“Early Expander”); an interaction between Early Expander and the year in which the policy was enacted (“Enact”); an interaction between Early Expander and all years after the year of enactment (“Implement”); a set of state-specific time-varying characteristics ( $\left.\mathrm{X}_{\mathrm{st}}\right)$; a set of year dummy variables; and state fixed effects. We consider each Early Expander state in a separate DD model, given the diversity in the early Medicaid expansions across the four Early Expander states. In Equation $1, \eta$ captures the average impact of the Medicaid expansion in a particular Early Expander state on federal disability outcomes since the expansion was implemented, while $\sigma$ reflects the anticipatory and firstyear effects of the policy change on outcomes.

$$
\begin{gathered}
y_{s t}=\text { Constant }+\gamma \text { Early_Expander }_{s}+\eta\left(\text { Early_Expander }_{s} X \text { Implement }_{t}\right) \\
+\sigma\left(\text { Early_Expander }_{s} X \text { Enact }_{t}\right)+X_{s t} \beta+\text { Year }_{t}+\text { State }_{s}+\epsilon_{s t} \quad \text { Eq. } 1
\end{gathered}
$$

\footnotetext{
${ }^{4}$ These states are: AR, IL, IA, KY, MD, NV, NJ, NM, ND, OH, OR, RI, WA, WV and WI.
} 
The advantage of the DD approach is that we can make a clean comparison, examining pre-post Medicaid expansion changes in federal disability outcomes in each state that expanded Medicaid early, netting out pre-post changes in federal disability outcomes in states that expanded Medicaid later, on January 1, 2014. We estimate linear probability models weighted by state population from the 2000 Census with Huber-White corrected standard errors adjusted for by clustering at the state level (Bertrand et al, 2004).

The DD model is based on the assumption that trends in states' federal disability outcomes in each of the Early Expander states would have been similar to those in the Later Expander states had the early expansion not been implemented. While this assumption cannot be tested directly, we can test whether trends in disability outcomes were different in each Early Expander state vs. the Later Expander states before the early Medicaid expansions took place. To do so, we estimate a version of Equation 1 which includes a set of interaction terms between Year and Early Expander. The specification is:

$$
y_{s t}=\sum_{j} \delta_{j} D_{t j}+X_{s t} \beta+\gamma_{s}+\gamma_{t}+\varepsilon_{s t} \quad \text { Eq. } 2
$$

where $y_{s t}$ is the outcome variable for state $s$ in year $t$; $D_{t j}$ is a dummy that turns on for a treated state $\mathrm{j}$ years after the treatment (negative if before); $X_{s t}$ are state level controls; $\gamma_{s}$ are state fixed effects; $\gamma_{t}$ are year fixed effects.; and $\varepsilon_{s t}$ is the error term. As we show below, these models indicate that in some cases, trends did vary between each Early Expander and Later Expanders in the years before the Medicaid expansion was enacted. For some outcomes, therefore, these findings do not support the assumption of similar trends in federal disability outcomes between Early Expanders vs. Later Expanders in the absence of the policy change.

For this reason, our main methodological approach in the paper is the synthetic control method. Details of this approach are provided in Abadie, Diamond \& Hainmueller (2010) and Abadie, Diamond, \& Hainmueller (2015). Here, we focus on intuitively describing this method and its application to our 
case. The heart of the synthetic control method lies in using a weighted average of comparison units, rather than a single comparison unit or an un-weighted combination of comparison units, as a better approximation of what would have happened to the treatment group in the absence of the treatment. Abadie, Diamond, \& Hainmueller (2015) motivate this idea by considering a sample which includes J + 1 units (for example, states). The unit $\mathrm{j}=1$ is the treated unit (for example, an Early Expander state) while units $\mathrm{j}=2$ to $\mathrm{j}=\mathrm{J}+1$ are the potential comparison units, called the “donor pool.” Abadie, Diamond, \& Hainmueller (2015) recommend that the donor pool be restricted to units with characteristics similar to those of the treated unit, and also to units that have not experienced a similar intervention as the treated unit. In this spirit, we limit the donor pool to Later Expander states, the 15 states that expanded Medicaid on January 1, 2014. ${ }^{5}$ We exclude from the donor pool the states that had earlier, extensive reforms, ${ }^{6}$ as well as states that either expanded Medicaid after January $12014,^{7}$ or have chosen not to expand Medicaid. ${ }^{8}$

Assuming that all units are observed in time periods $t=1, \ldots . \mathrm{T}$, the number of preintervention time periods is $\mathrm{T}_{0}$, and the number of post-intervention time periods is $\mathrm{T}_{1}$, so that $\mathrm{T}=\mathrm{T}_{0}+$ $\mathrm{T}_{1}+1$ (adding the year of the intervention). In our case, the data span 2000 to 2013; the pre-intervention period is 2000-2009 for CT and DC, while for CA and MN, the pre-intervention period is 2000-2010. ${ }^{9}$ Abadie, Diamond, \& Hainmueller (2015) propose that a synthetic control can be represented by a (Jx1) vector of weights $\mathrm{W}=\left(\mathrm{w}_{2}, \ldots \ldots . . \mathrm{w}_{\mathrm{j}+1}\right)^{\prime}$ with $0 \leq \mathrm{w}_{\mathrm{j}} \leq 1$ for $\mathrm{j}=2, \ldots . \mathrm{J}$ and $\mathrm{w}_{2}+\ldots \ldots+\mathrm{w}_{\mathrm{j}+1}=1$. In choosing $\mathrm{W}$, the goal is to match pre-intervention characteristics of the synthetic control group as closely as possible to the treatment group. If $\mathrm{X}_{1}$ is a ( $\left.\mathrm{k} \mathrm{x} 1\right)$ vector containing pre-intervention

\footnotetext{
${ }^{5}$ These states are: AR, IL, IA, KY, MD, NV, NJ, NM, ND, OH, OR, RI, WA, WV and WI. Note that in Wisconsin, childless adults at $100 \%$ or less of the FPL are eligible; this threshold is below the ACA expansion level of $138 \%$ of the FPL.

${ }^{6}$ These states include MA, NY, AZ, CO, DE, HI, and VT.

${ }^{7}$ These states are: AK (9/1/15), IN (2/1/15), MI (4/14), NH (8/15/14), PA (1/1/15); MT (1/1/16). Source: http://kff.org/health-reform/state-indicator/state-activity-around-expanding-medicaid-under-the-affordable-careact/\#note-1

${ }^{8}$ These states include AL, FL, GA, ID, KS, LA, ME, MS, MO, NE, NC, OK, SC, SD, TN, TX, UT, VA, and WY. As of January 2016, childless adults are not eligible for Medicaid in any of these states.

${ }^{9}$ For the SSI application and SSI award outcomes, the data start in 2002.
} 
characteristics of the treated unit, and $\mathrm{X}_{0}$ is a $(\mathrm{k} \mathrm{x} \mathrm{J})$ matrix containing these same characteristics for the donor pool, then the optimal synthetic control $\mathrm{W}^{*}$ is the value of $\mathrm{W}$ that minimizes:

$$
\sum_{m=1}^{k} v_{m}\left(X_{1 m}-X_{0 m} W\right)^{2} \quad \text { Eq. } 3
$$

In Equation 3 above, $X_{1 m}$ represents the value of the $m$ th variable $(m=1, \ldots k)$ for the treated unit and $\mathrm{X}_{0 \mathrm{~m}}$ represents the $(1 \mathrm{x} \mathrm{J})$ vector containing the values of the mth variable for the donor pool units. The pre-intervention characteristics used in this analysis are the following variables averaged over the pre-intervention period: percent of state with four year college degree; percent of state between 45-54 years old; percent of state between 55-64 years old; percent unemployed; percent living at or below the FPL; and the outcome variable. The term $v_{\mathrm{m}}$ captures the weight given to the mth characteristic. These weights are based on how well each characteristic predicts the outcome, with larger weights placed on characteristics that have more predictive power. ${ }^{10}$

Finally, letting $\mathrm{Y}_{1}$ be a vector of post-intervention outcomes for the treatment group and letting $\mathrm{Y}_{0}$ be a matrix of post-intervention outcomes for the donor pool, the synthetic control estimator of the effect of the treatment is the difference $\mathrm{Y}_{1}-\mathrm{Y}_{0} \mathrm{~W}^{*}$. Essentially, the synthetic control estimator involves comparing the outcome in the treated unit (which was exposed to the policy intervention) to the synthetic control (not exposed to the policy intervention) during the post-intervention period.

Inference in the context of synthetic control methods has been conducted using falsification tests. The underlying idea is that, if we find, for example, what seems to be a large effect of the Medicaid expansion on a federal disability outcome in an Early Expander state, we would have more confidence in this result if this effect still appeared large compared to what we find when we use each of the Later Expander states as an Early Expander state in a synthetic control falsification exercise. In

\footnotetext{
${ }^{10}$ We use the synth command in STATA 13 to implement the synthetic control method. The default option in synth uses a constrained quadratic programming method to find the optimal $\mathrm{W}$ conditional on a regression-based $v$ matrix. There also is a nested option in STATA 13 which optimizes over all possible sets of $v$ and W for the best synthetic control. However, the nested method did not work well for some states in this analysis. If we use the nested approach, for states with the largest DI/SSI rates, we cannot find a synthetic control state, because the optimization algorithm reaches a flat area and the STATA program ends with an error. If we delete the state that led to the error, we will have the same error message for another state (likely the one has the second largest DI/SSI rate).
} 
other words, we would only have confidence in a finding if the true effect were large relative to the distribution of false effects generated from falsely assigning each of the Later Expander states as a treatment state.

Following Abadie, Diamond \& Hainmueller (2010), we conduct inference in the following manner. First, we use the synthetic control methods and compute treatment effects, as described above. The treatment effects are estimated for all outcomes and for each of the four Early Expander states. Next, we conduct a falsification exercise for each outcome and each Early Expander state. To do so, we take each of the 15 Later Expander states in the donor pool one by one, treat each of these states as if it were an Early Expander state (the true treatment state is included in the donor pool as well for this exercise), and re-calculate synthetic control estimates. The synthetic control method works better in terms of matching on pre-intervention characteristics for some states versus other states. That is, the mean square prediction error (MSPE) in the pre-intervention period is lower for some states, in which the matching worked well, versus other states, in which the matching did not work as well. ${ }^{11}$ Thus, what is relevant is the ratio of the MSPE during the post-intervention period to the MSPE during the preintervention period, since this ratio provides information regarding how closely the treatment group’s outcomes matched the synthetic control post-intervention, relative to how well the matching worked preintervention. A relatively high MSPE ratio indicates worse matching between the treated state and the synthetic control in the post-intervention period relative to what would be expected given the quality of the matching in the pre-intervention period. This is what we would expect if there is an effect of the intervention on the outcome.

We compare the MSPE ratio for each Early Expander state to the MSPE ratios calculated for Later Expander states when each Later Expander state is used as a fake treated state in a falsification exercise. The p-value is calculated based on the MSPE ratio for each treated state and for each state in the donor pool when it is falsely assigned as the treated state. The p-value is the number of states with a

${ }^{11}$ The MSPE is calculated as: $\left(1 / T_{0} \sum_{t=1}^{T_{0}}\left(Y_{i t}-\sum_{j=2}^{J+1} w_{j}^{*} Y_{j t}\right)^{2}\right)$. 
MSPE at least as high as the true treated state plus one (to include the treated state) divided by 16, which is the number of donor states plus the treated state. For example, if CT has the highest MSPE ratio for a particular outcome when each of the 15 donor states is treated as a treatment state in a falsification exercise, then we would calculate the p-value as $1 / 16$ or 0.0625 . In this manner, we can compute pvalues for each of our estimated synthetic control effects.

\section{Data}

Our main dependent variables are federal disability outcomes measured at the state-year level for the time period 2000 to 2013. These measures are: percent of state applying for SSI benefits; percent of state awarded SSI benefits; percent of state receiving SSI benefits; percent of state awarded DI worker benefits; and percent of state receiving DI worker benefits. ${ }^{12}$ These dependent variables are constructed by dividing the number of applications, awards, and beneficiaries in the state by December $31^{\text {st }}$ of each year by the state-level population estimate for age group 18-64 as of July 1 for that year, multiplying by 100. The numbers of SSI applicants, awards, and beneficiaries come from the following reports available from the Social Security Administration -- SSI Recipients by State and County 20002013, and the SSI Annual Statistical Report, 2002-2013. The numbers of DI awards and beneficiaries come from Annual Statistical Report on the Social Security Disability Insurance Program, 2000-2013. Population estimates for each year come from the Census. The SSI application and SSI award data are available from 2002-2013, while the other outcomes are available for the whole time period, 2000-2013.

We also examine several dependent variables that may be mechanisms linking Medicaid expansions to federal disability outcomes. When possible, given the data available, we focus on the population targeted by the ACA Medicaid expansions -- childless adults aged 18-64 with family income below 200 percent of the FPL. These variables are: percent of state’s childless, low-income 18-64 year old population that is uninsured; percent of state's childless, low-income 18-64 year old population with

\footnotetext{
${ }^{12}$ Worker DI benefits refer to disabled workers who claim disability benefits based on their own earnings records. Data on worker DI applications are not available.
} 
ESHI; percent of state's childless, low-income 18-64 year old population with Medicaid; and percent of state’s population 18 years old and older in fair or poor health. The insurance data for childless, lowincome adults are available for 2008-2013 only.

To capture population growth, we also consider the state's population in the current year divided by population in the year 2000 x 100 . To measure net migration of childless, poor individuals into a state, we use data from the American Community Survey (ACS) 2000-2013 on current state of residences and previous year's state of residence. Net migration is the number of people migrating into the state (from other states and abroad) minus the number of people migrating out of the state to other states (we do not have information on those who migrate abroad), divided by population in 2000, multiplied by 100. The health insurance data, and the time-varying state level controls, are constructed from the ACS, 2000-2013. The controls are: the percent of state aged 45-54; the percent of state aged 55-64; the percent of state aged 25+ with 4 -year college degree; the percent of state with income at or below the FPL; and the unemployment rate. The health data come from the Behavioral Risk Factor Surveillance System.

\section{Results}

\subsection{Difference-in-Difference Findings for Disability Outcomes and Mechanisms}

Table 2 shows DD estimates for the SSI outcomes (Panel A) and for the DI outcomes (Panel B). For the SSI outcomes, there is a consistent pattern of findings for CT and CA. In these two states, the ACA Medicaid expansion is associated with a decline in SSI applications, awards, and recipients. This association is not consistently statistically significant, however, for any of the SSI outcomes except SSI recipients. In CT and CA, the early Medicaid expansion is associated with 0.11 and 0.28 percentage point, post-policy reductions in the percent of the state receiving SSI, respectively, which represent about 7 and 11 percent declines relative to the pre-policy period means. Notably, the magnitudes of these findings are similar to what Burns \& Dague (2016) report for SSI receipt (a 7 percent reduction, 
based on DD methods), although these authors focus on a broader set of Medicaid expansions, and they are able to limit their sample to childless adults (which we cannot do for the disability outcomes).

In MN, the association between the Medicaid expansion and SSI outcomes is negative in sign in all but one model, but not significantly different from zero (Panel A, Table 2). In DC, in contrast to the results for the other three states, the ACA Medicaid expansion is positively associated with SSI applications, awards, and recipients, and these associations are statistically significant for awards and recipients (Panel A, Table 2). The expansion in DC is associated with a 0.18 percentage point increase in SSI awards, a 34 percent increase at the pre-policy mean, and a 0.43 increase in SSI recipients, a 13 percent increase at the pre-policy mean (Panel A, Table 2).

Panel B of Table 2 shows the DD results for the DI outcomes. In CT, CA, and MN, the ACA Medicaid expansion is negatively associated with DI awards and recipients, and these effects are statistically significant in most cases. The Medicaid expansion is associated with reductions in DI recipients in the post-policy period of 9-16 percent, evaluated at the pre-policy means. In DC, as was the case with SSI outcomes, we see a different pattern of findings. There appears to be no consistent association between Medicaid expansion and DI outcomes in DC (Panel B, Table 2).

The reduction in disability recipients in CT, CA, and MN may come about because now lowincome disabled individuals can access public health insurance without receiving SSI benefits or perhaps because having access to Medicaid improves health enough to continue working. On the other hand, in DC, the Medicaid expansion may have increased SSI awards and recipients because the expansion changed migration patterns, attracting a more disabled population. In Table 3, we examine the plausibility of these mechanisms. Panels A-C in Table 3 show findings from DD models of insurance outcomes among low-income, childless adults (percent uninsured, percent with ESHI, percent with Medicaid) while Panels D and E show results from models of overall health among adults aged 18 and over (Panel D) and models of population growth among adults aged 18-64 (Panel E). In Panel F in 
Table 3, we show findings from a model of net migration of low-income, childless adults specifically. Each column in Table 3 shows models for a particular state - CT, DC, CA or MN.

In CT, the Medicaid expansion was associated with a 5 percentage point increase in the probability of having Medicaid, a 1 percentage point reduction in the likelihood of being uninsured, and a 2 percentage point decrease in the probability of having ESHI, among low-income, childless adults (Table 3, Panels A-C). This is consistent with the hypothesized impact of a Medicaid expansion (increased Medicaid participation, and crowd-out of ESHI), although the effect on un-insurance is not statistically significant (Table 3, Panel A). There is no apparent effect of the Medicaid expansion on the probability of being in fair or poor health in CT, although this regression is not limited to low-income childless adults, and the health measure is somewhat crude (Table 3, Panel D). Nevertheless, based on this limited health measure, we do not find any evidence that improved health is the mechanism leading from the Medicaid expansion to the decline in SSI recipients in CT. The results in Table 3 do not show an association between the Medicaid expansion and population growth in CT. The findings do suggest, however, that in 2010, the year in which the Medicaid expansion went into effect in CT, there was an increase in net migration of low-income, childless adults into CT (Panel F, Table 3).

In DC, we see a similar, intuitive pattern of effects of the Medicaid expansion on insurance outcomes among low-income, childless adults (a reduction in ESHI and un-insurance, and an increase in Medicaid), but only one of these associations (percent with ESHI) is statistically significant (Table 3, Panels A-C). There is no statistically significant association between the Medicaid expansion and overall health or population growth in DC (Table 3, Panels D and E). As we saw in CT, however, the Medicaid expansion in DC is associated with increased migration of low-income, childless adults in 2010 into DC, the year in which the expansion became effective in DC (Table 3, Panel F).

In CA, while most estimated coefficients are intuitive in sign, none of the estimated associations between the Medicaid expansion and insurance outcomes, or overall health, are statistically different from zero. The Medicaid expansion is associated with an increase in population growth (Panel 
E, Table 3), which may have affected our findings since the disability outcome variables are measured in percentages, and population is the denominator. Nevertheless, the Medicaid expansion is not associated with net migration of low-income, childless adults into CA (Panel F, Table 3).

Finally, in MN, the descriptive pattern of findings for insurance outcomes among low-income, childless adults is intuitive, but the only finding that is statistically significant is that the Medicaid expansion is associated with about a 1 percentage point increase in Medicaid coverage. The Medicaid expansion is associated with a statistically significant increase in population growth in MN, but, perversely, the expansion is also associated with a statistically significant decline in net migration of low-income, childless adults into MN (Panel F, Table 3).

In sum, the pattern of DD findings in Tables 2 and 3 suggests that early Medicaid expansions are associated with reductions in the number of SSI and DI recipients in CT and CA. In MN, the Medicaid expansion was associated with reductions in DI, but had no association with SSI outcomes. In contrast, in DC, the expansion was associated with increases in SSI awards and recipients (which may stem from changes in migration patterns induced by the expansion), and no effect on DI outcomes.

When we examine pre-period trends in these outcomes between each treated state vs. the control states, however, these trends cast some doubt on the validity of the DD approach. These pre and post trends for each of the five outcome variables for each treatment state (CT, CA, DC, and MN) vs. the control states are shown in Appendix Figures 1-5. In some cases, these figures show differences in trends in outcomes in the pre-policy time period. For example, in DC, there is an upward trend in all SSI outcomes relative to control states prior to the Medicaid expansion, and generally, there is the most noise in the data from DC (Appendix Figures 1-5). On the other hand, the SSI recipients and DI recipients outcomes are fairly stable in all states but DC, and the pre-period trend appears very similar to that of the comparison group, at least for MN and CA, and possibly also for CT (Appendix Figures 3 and 5). For the mechanisms (insurance coverage, overall health, and population growth), we also see that the pre-period trend is very similar in the treated state vs. the comparison states for some outcomes 
and states, but not for other outcomes and states (results available upon request). If pre-period trends differ between each treatment state and its controls, the parallel trends assumption underlying the DD method is suspect. Thus, we interpret the DD findings with caution, and move to the synthetic control method.

\subsection{Synthetic control findings}

First, we examine the synthetic control weights generated for each outcome and each treatment state. Table 4 shows the weights generated for every outcome for CT. The weights for the five outcomes for the other three states are shown in Appendix Table 1 (DC), Appendix Table 2 (CA) and Appendix Table $3(\mathrm{MN})$. Since much of the matching is driven by the average rate of disability receipt (the outcome variable) in the pre-policy period, one would not necessarily expect that the synthetic control would be weighted towards states that are geographically close to the treated state. From Table 4, we see that for the SSI applications outcome in CT, a combination of MD, NJ and WV is the optimal comparison state based on how well the pre-period trend in SSI applications can be reproduced. All other states receive zero weight for this outcome. For the other outcomes in CT, the synthetic control is different in each case, but in general, $\mathrm{NJ}$ is a state that is weighted heavily for all outcomes. As can be seen in Table 4 and in Appendix Tables 1-3, for all states and all outcomes, there are only a few states that comprise each synthetic control, with all other states in the donor pool receiving zero weight. In one case (the DI recipients outcome for CA), only one state is used as the synthetic control (MD in this case).

Figures 1-5 show trends in the SSI and DI outcomes in each treatment state relative to its synthetic control for the time period 2000-2013 or 2002-2013, depending on the outcome, with the pre vs. post policy period demarcated by a vertical line. Overall, these figures show that the pre-policy trends in the synthetic controls match the trends in the treated states fairly well, but there is considerable variation across states and outcomes. In general, the match between the synthetic control and the treated state is better when there is less yearly volatility in the data. For the SSI applications and SSI awards 
outcomes, for example, the pre-period match is worse for DC than for CT, CA and MN because the rates move around more from year to year in DC (Figures 1 and 2). For the SSI recipient outcome, the preperiod match between the synthetic control and the treated state is very good for all states, and especially for CT since the data are quite stable in the pre-policy period (Figure 3). For the DI award outcome, the quality of the year-by-year match between the synthetic control and the treated state in the pre-period does not appear to be good for CA (Figure 4), but it is almost a perfect match for the DI recipient outcome in MN (Figure 5).

Table 5 provides more detailed information regarding the quality of the match between the synthetic control and its real counterpart for all disability outcomes in CT. The table displays pre-policy period means for CT, the average of the 15 control states, and the synthetic control. From this table, it is clear that the synthetic control substantially improves the matching on the average pre-period characteristics of CT, particularly matching on the outcome variable in the pre-period which is weighted heavily due to its importance as a predictor. In fact, in the case of CT, the match on the average characteristics in the pre-policy period is excellent for all of the characteristics that we consider.

Appendix Tables 4, 5, and 6 show the same information for DC (Appendix Table 4), CA (Appendix Table 5), and MN (Appendix Table 6). For DC, the matching on the average of each disability outcome variable in the pre-policy time period was excellent, with the synthetic control matched almost perfectly with DC on this characteristic. The match on the "percent with a college degree” and the "percent living in poverty" was not as good, since DC has an unusual combination of a highly educated population but a relatively large fraction of the population living in poverty (Appendix Table 4). For CA (Appendix Table 5) and MN (Appendix Table 6), the match between the synthetic control and the treated state was excellent for all characteristics measured in the pre-period. Thus, from Table 5 and Appendix Tables 4-6, we conclude that the synthetic control method's matching on average characteristics in the pre-period worked very well for CT, CA, and MN, and was somewhat less successful in DC for characteristics other than the outcome variables. 
The synthetic control estimate of the effect of the Medicaid expansion on each outcome is the average difference between the synthetic control and the treatment state for each outcome during the post-policy period. This can be viewed graphically by turning back to Figures 1-5. Across these five figures, we see the most consistent pattern for CT. In every figure for CT, there is a decline in the outcome in CT relative to the synthetic control during the post policy period, suggesting that the Medicaid expansion is associated with reductions in SSI applications, SSI and DI awards, and SSI and DI recipients. This is quite consistent with the pattern of DD findings for CT in Table 2.

For the other three treatment states, the patterns in Figures 1-5 are more mixed. In CA, as we saw in CT, there appears to be a reduction in SSI recipients, DI awards and DI recipients relative to the synthetic control during the post-policy period (Figures 3-5). In CA, however, the synthetic control does not match the true CA well for DI awards and DI recipients during the pre-policy period, making it hard to draw conclusions about the effect of the Medicaid expansion (Figures 4-5). In MN, the trends in all of the SSI outcomes lie slightly above the synthetic control after Medicaid expansion, suggesting the Medicaid expansion increases SSI applications and caseloads (Figures 1-3). We only see, however, a tiny increase of DI recipients in MN (Figure 5).

Table 6 summarizes synthetic control findings for all outcomes and states. The table displays the average of the difference in the mean outcome between each treated state and its synthetic counterpart during the entire post-policy period. The p-value reported in Table 6 is generated based on results from the falsification tests involving each state in the donor pool; it is the number of states with a MPSE at least as high as the treated state (plus one) divided by 16, which is the number of states in the donor pool (15) plus the treated state.

Column 1 in Table 6 summarizes findings for CT. In CT, the Medicaid expansion in 2010 is associated with declines in all disability outcomes - the expansion is associated with a marginally statistically significant, 0.11 percentage point reduction in SSI recipients, which is a 7 percent reduction at the pre-expansion mean. This estimate is the same as what we found using DD methods - a 
statistically significant, 0.11 reduction in SSI recipients (Table 2) ${ }^{13}$ Also, this magnitude is the same as what Burns \& Dague (2016) report for SSI receipt (a 7 percent reduction), although these authors focus on a broader and different set of Medicaid expansions. Based on the synthetic control method, the association between the Medicaid expansion and the other disability outcomes are not statistically significant at conventional levels in CT.

In Column 2 of Table 6, we show the same set of findings for DC. In DC, none of the synthetic control findings are statistically significant, and the signs of the effects are inconsistent. In Figures 2 and 3, there is an increase in SSI awards and recipients in DC relative to its synthetic control during the post-policy period; these effects were statistically significant in the DD models in Table 2. In Column 2 of Table 6, these associations are positive and large in magnitude, but not statistically significant. The pattern of findings may suggest that the Medicaid expansion attracted low-income migrants from other states who qualified for SSI, as we saw in the DD models in Panel F of Table 3.

Columns 3 and 4 in Table 6 summarize synthetic control findings for CA (Column 3) and MN (Column 4). In CA, we observe that the Medicaid expansion is associated with about a 20 percent reduction in DI receipt, and a 6 percent reduction in SSI receipt. These synthetic control estimates are not statistically significant at conventional levels; however, these magnitudes are similar to the DD estimates for CA in Table 2, which were statistically significant.

Finally, in MN (Column 4 in Table 6), we see a mixed pattern of synthetic control findings. The expansion has a positive association with all SSI outcomes, and a positive association with DI recipients, but a negative association with DI awards. None of these effects, however, are statistically different from zero, even though the positive association between the Medicaid expansion and SSI recipients is large in magnitude (representing a 16 percent increase at the pre-policy mean).

\footnotetext{
${ }^{13}$ The MSPE ratio for CT vs. the MSPE ratio for every state in the donor pool when it is treated as "fake" treatment state is shown in Appendix Figure 6. North Dakota may have a high MSPE ratio because the Medicaid expansion in CT took place at the same time when population changes were taking place in North Dakota due to the oil boom.
} 
We attempted to apply synthetic control methods to the models of insurance outcomes, population growth, and net migration. However, the synthetic control methods did not work well for these mechanism variables, with the exception of total population growth. This is because the year to year variation due to measurement error was large for these survey averages. Moreover, the insurance data start in 2008, giving us only a very short pre-policy time period.

\section{Discussion and Conclusions}

As of December 2014, about 9 million disabled workers received DI benefits, costing about \$142 billion in DI benefit payments, and about 8 million individuals received SSI benefits, costing about \$55 billion in SSI benefit payments (Social Security Administration, 2016b). Since the early 1970’s, the number of SSI recipients has more than doubled, and the percentage of working-age individuals receiving DI benefits based on their own disability and earnings history has more than tripled (Center on Budget and Policy Priorities, 2014; CBO, 2016). In addition, the composition of the SSI population has shifted over the last three decades, from being comprised primarily of low-income, elderly people to including a larger proportion of younger people with disabilities, particularly psychiatric disabilities (Center on Budget and Policy Priorities, 2014). Given the size, cost, and changing composition of the federal disability caseloads, there has been concern that many disabled individuals who could work instead seek disability benefits to gain access to public health insurance. The early Medicaid expansions in CT, DC, CA and MN allow us to test whether broader access to Medicaid is associated with applications for, awards for, and receipt of federal disability benefits. If access to Medicaid is an important motivation for disability enrollment, one would expect that expanding Medicaid would reduce disability caseloads. Since there are other potential pathways linking Medicaid expansions to disability receipt, however, the relationship between broader Medicaid eligibility and federal disability caseloads is not clear-cut. 
Most previous researchers have used DD methods to examine the effects of Medicaid expansions. When we apply DD methods, we have a consistent pattern of findings for CT, CA, and MN - in these three states, Medicaid expansions are associated with reductions in DI and SSI receipt. In DC, the DD findings suggest that the Medicaid expansions are associated with an increase in SSI receipt. This finding may be explained by migration of low-income, childless adults to DC induced by the expansion. Inspection of pre-period trends in outcomes, however, casts some doubt on the credibility of the DD approach. In many cases, there are pre-policy differences between the treated state and the comparison group in trends in the outcome variables.

For this reason, we move to synthetic control methods recently introduced Abadie et al. (2010). The findings from this method are generally qualitatively consistent with the DD findings, but not statistically different from zero. The one exception is CT’s Medicaid expansion - for this state, we find a consistent pattern of findings across DD and synthetic control methods, indicating that the expansion was associated with a 7 percent reduction in SSI recipients. In CT, the early Medicaid expansion shifted childless adults with incomes below 56\% of the FPL from a state-financed, limited health insurance program to Medicaid, substantially expanding benefits (Nikpay et al., 2015). Although SSI and Medicaid are not explicitly linked in CT, this change may have induced some disabled, low-income individuals to continue working or resume working, reducing their need for disability benefits. The mechanisms underlying this shift are hard to capture using secondary data. Our findings do show that the Medicaid expansion in CT was associated with an increase in Medicaid participation among lowincome childless adults. We find no effects, however, of the CT Medicaid expansion on health, but our health measure is crude, and the sample for this analysis is not limited specifically to low-income, childless adults.

The main lesson we can draw from these findings is that the effects of Medicaid expansions on federal disability outcomes are likely to be heterogeneous across states. Also, we emphasize that the early Medicaid expansions that we study differ from those that have taken place more recently, 
suggesting that effects on federal disability outcomes may be different as well. The more recent ACA Medicaid expansions initiated since 2014 differ from the early expansions in CT, MN, CA, and DC in that the early expansions built on previous state-run programs; had income thresholds lower than $138 \%$ of FPL (in the case of CT and MN); and were implemented in states in which the political climate was supportive of the ACA (Somers et al., 2013). As data become available, it is important that researchers examine the effects of the more recent Medicaid expansions in 2014 on federal disability outcomes. 
References

1. Abadie, A., Diamond, A. \& Hainmueller, J.. (2010). Synthetic control methods for comparative case studies: Estimating the effect of California's tobacco control program. Journal of the American Statistical Society, 105(490): 493-505.

2. Abadie, A., Diamond, A. \& Hainmueller, J.. (2015). Comparative politics and the synthetic control method. American Journal of Political Science, 59(2): 495-510.

3. The Arc of the United States (August 2012), The ACA: What disability advocates need to know. Accessed at: http://www.scdd.ca.gov/res/docs/pdf/Whats_New/The\%20Affordable\%20Care\%20Act\%20What \%20Disability\%20Advocates\%20Need\%20to\%20Know.pdf, August 2016.

4. Bertrand, M., Duflo, E. \& Mullainathan, S. (2004). How much should we trust differences in differences estimates? The Quarterly Journal of Eonomics, 119(1): 249-275.

5. Bitler, M. \& Zavodny, M (May 2014). Medicaid: A review of the literature. National Bureau of Economic Research Working Paper 20169.

6. Burns, M., \& Dague, L.. (2016). The effect of expanding Medicaid eligibility on Supplemental Security Income program participation. Working paper.

7. Center on Budget and Policy Priorities, (February 2014). Introduction to the Supplemental Security Income (SSI) Program. Available at: http://www.cbpp.org/sites/default/files/atoms/files/1-10-11socsec.pdf.

8. Congressional Budget Office, US Congress (June 2016). Social Security Disability Insurance: Participation and Spending. Available at: https://www.cbo.gov/sites/default/files/114thcongress-2015-2016/reports/51443-SSDI_Participation_Spending.pdf.

9. Finkelstein, A., Taubman, S., Wright, B., Bernstein, M., Gruber, J., Newhouse, J.P., Allen, H. \& Baicker, K. (2012). The Oregon Health Insurance Experiment: Evidence from the First Year. Quarterly Journal of Economics 127(3): 1057-1106.

10. Frean , M., Gruber, J. \& Sommers, B.D.. (April 2016) Premium subsidies, the mandate, and Medicaid expansion: Coverage effects of the Affordable Care Act. National Bureau of Economic Research Working Paper 22213.

11. Golberstein, E., Gonzales, G. \& Sommers, B.D. (2015). California’s early ACA expansion increased coverage and reduced out-of-pocket spending for the state's low-income population. Health Affairs 34(10): 1688-1694.

12. Gruber, J. Health insurance and the labor market. 2000. In: Handbook of Health Economics, vol. 1A (Culyer, A.J \& Newhouse, J.P. Eds.). Elsevier: Amsterdam.

13. Gruber, J. \& Kubik, J. (September 2002). Health insurance coverage and the disability insurance application decision. National Bureau of Economic Research Working Paper 9148. 
14. Gruber, J. \& Madrian, B.C. (September 1993) Limited insurance portability and job mobility: The effects of public policy on job lock. National Bureau of Economic Research Working Paper 4479. Cambridge, MA.

15. Hu, L., Katesner, R., Mazumder, B., Miller, S., \& Wong A. The effects of the Patient Protection and Affordable Care Act Medicaid expansions on financial well-being. National Bureau of Economic Research Working Paper 22170, April 2016.

16. Kaiser Family Foundation (September 2012) Focus on Health Reform. Health insurance market reforms: Pre-existing condition exclusions.

17. Kaiser Family Foundation, March 20, 2015. Medicaid enrollment and the Affordable Care Act.

18. Kaiser Family Foundation, March 14, 2016, Status of state action on the Medicaid expansion decision. Available at: http://kff.org/health-reform/state-indicator/state-activity-aroundexpanding-medicaid-under-the-affordable-care-act/

19. Kaestner, R., Garrett, B., Gangopadhyaya, A., \& Fleming, C.. Effects of ACA Medicaid expansions on health insurance coverage and labor supply. National Bureau of Economic Research Working Paper 21836, December 2015.

20. Kennedy, J. \& Blodgett, E. (September 20, 2012). Health insurance-motivated disability enrollment and the ACA. New England Journal of Medicine, 367:e16.

21. Maestas, N., Mullen, K.J. \& Strand, A.. (2014). Disability insurance and health insurance reform: Evidence from Massachusetts. American Economic Review: Papers and Proceedings, 104(5): 329-335.

22. McInerney, M. (2013). The Medicaid buy-in and Spcial Security Disability Insurance (DI) beneficiaries: Lessons for the 2014 Medicaid expansion and proposals to reform DI. Center for Retirement Research at Boston College CRR WP 2013-20.

23. Nikpay, S., Buchmueller, T \& Levy, H. (2015). Early Medicaid expansion in Connecticut stemmed the growth in hospital uncompensated care. Health Affairs, 34(7): 1170-1179.

24. Peele, P. S., J. R. Lave, K. J. Kelleher. 2002. “Exclusions and Limitations in Children’s Behavioral Health Care Coverage.” Psychiatric Services. 33:591-594.

25. Schwartz, A.L. \& Sommers, B.D. (2014). Moving for Medicaid? Recent eligibility expansions did not induce migration from other states. Health Affairs, 33(1): 88-94.

26. Social Security Administration, 2016a, https://www.ssa.gov/disabilityresearch/wi/medicaid.htm.

27. Social Security Administration, (August 2006). Trends in the Social Security and Supplemental Security Income Disability Programs, https://www.ssa.gov/policy/docs/chartbooks/disability trends/. 
28. Social Security Administration, (April 2016b), Annual statistical supplement to the Social Security Bulletin, 2015. Available at:

https://www.ssa.gov/policy/docs/statcomps/supplement/index.html.

29. Somers, S.A., Hamblin, A., Verdier, J.M. \& Byrd, V.L.H. (2010). Covering low-income childless adults in Medicaid: Experiences from selected states. Center for Health Care Strategies Policy Brief, August 2010.

30. Sommers, B.D., Kenney, G.M. \& Epstein, A.M. (2014). New evidence on the Affordable Care Act: Coverage impacts of early Medicaid expansions. Health Affairs, 33(1): 78-87.

31. Sommers, B.D., Chua, K., Kenney, G.M., Long, S.K. \& McMorrow, S.. (2016) California’s early coverage expansion under the Affordable Care Act: A county-level analysis. Health Services Research, 51(3): 825-845.

32. Sommers, B.D., Arnston, E., Kenney, G.M. \& Epstein, A.M.. (2013) Lessons from early Medicaid expansions under health reform: Interviews with Medicaid officials. Medicare \& Medicaid Research Review, 3(4): E1-E19.

33. Wagner, K.L. (2015). Medicaid expansions for the working age disabled: Revisiting the crowdout of private health insurance. Journal of Health Economics, 40, 69-82. 
Table 1: Early Medicaid expansions in California, Connecticut, District of Columbia and Minnesota

\begin{tabular}{|c|c|c|}
\hline State & Date and year of expansion & Details regarding expansion \\
\hline California & July 1, 2011 & $\begin{array}{l}\text { Childless, non-disabled, legal } \\
\text { residents up to } 200 \% \text { of FPL; } \\
\text { varies by county }\end{array}$ \\
\hline Connecticut & April 1, 2010 & $\begin{array}{l}\text { Childless, non-disabled adults } \\
\text { under } 56 \% \text { of FPL who had } \\
\text { been on State General Medical } \\
\text { Assistance; maintains } \$ 150 \text { per } \\
\text { month earnings disregard }\end{array}$ \\
\hline District of Columbia & July 1, 2010 & $\begin{array}{l}\text { Childless, non-disabled adults } \\
\text { below } 200 \% \text { of FPL }\end{array}$ \\
\hline Minnesota & March 1, 2011 & $\begin{array}{l}\text { Previously state-funded General } \\
\text { Medical Assistance patients } \\
\text { under } 75 \% \text { of FPL }\end{array}$ \\
\hline
\end{tabular}

Source: Sommers, B.D., Arnston, E., Kenney, G.M. \& Epstein, A.M.. (2013) Lessons from early Medicaid expansions under health reform: Interviews with Medicaid officials. Medicare \& Medicaid Research Review, 3(4): E1-E19. 
Table 2: Effects of early Medicaid expansions on SSI and DI applications, awards, and number of beneficiaries - DD estimates

\begin{tabular}{|c|c|c|c|c|c|c|c|c|c|c|c|c|}
\hline & \multicolumn{12}{|c|}{ Panel A: SSI Outcomes } \\
\hline & \multicolumn{4}{|c|}{ Applications } & \multicolumn{4}{|c|}{ Awards } & \multicolumn{4}{|c|}{ Recipients } \\
\hline & $\mathrm{CT}$ & DC & CA & $\mathrm{MN}$ & $\mathrm{CT}$ & DC & CA & $\mathrm{MN}$ & $\mathrm{CT}$ & DC & CA & $\mathrm{MN}$ \\
\hline \multirow[t]{2}{*}{ Treat X Year implemented } & -0.05 & 0.04 & $-0.07 * *$ & -0.01 & $-0.04 * * *$ & $0.10 *$ & -0.01 & -0.02 & $-0.09 * *$ & 0.19 & $-0.18 * * *$ & -0.04 \\
\hline & $(0.03)$ & $(0.08)$ & $(0.03)$ & $(0.02)$ & $(0.01)$ & $(0.05)$ & $(0.02)$ & $(0.02)$ & $(0.03)$ & $(0.16)$ & $(0.04)$ & $(0.05)$ \\
\hline \multirow[t]{2}{*}{ Treat X Post } & -0.02 & 0.15 & $-0.09 * * *$ & 0.03 & $-0.03^{*}$ & $0.18 * *$ & $-0.02 *$ & -0.01 & $-0.11 * *$ & $0.43 * *$ & $-0.28 * * *$ & -0.07 \\
\hline & $(0.03)$ & $(0.10)$ & $(0.03)$ & $(0.02)$ & $(0.02)$ & $(0.07)$ & $(0.01)$ & $(0.02)$ & $(0.05)$ & $(0.17)$ & $(0.05)$ & $(0.06)$ \\
\hline Pre-policy period means & 0.788 & 1.31 & 0.871 & 0.694 & 0.224 & 0.529 & 0.287 & 0.220 & 1.53 & 3.21 & 2.58 & 1.45 \\
\hline \multirow[t]{4}{*}{$\mathbf{N}$} & \multicolumn{8}{|c|}{192} & \multicolumn{4}{|c|}{224} \\
\hline & \multicolumn{12}{|c|}{ Panel B: DI Outcomes } \\
\hline & & & & & \multicolumn{4}{|c|}{ Awards } & \multicolumn{4}{|c|}{ Recipients } \\
\hline & & & & & $\mathrm{CT}$ & DC & CA & $\mathrm{MN}$ & $\mathrm{CT}$ & DC & CA & $\mathrm{MN}$ \\
\hline \multirow[t]{2}{*}{ Treat X Year implemented } & & & & & $-0.06 * * *$ & 0.00 & -0.01 & $-0.05^{*}$ & $-0.27 * * *$ & -0.26 & $-0.25 * * *$ & $-0.21 * *$ \\
\hline & & & & & $(0.01)$ & $(0.05)$ & $(0.02)$ & $(0.02)$ & (0.09) & $(0.45)$ & $(0.06)$ & $(0.08)$ \\
\hline \multirow[t]{2}{*}{ Treat X Post } & & & & & $-0.05 * * *$ & 0.01 & -0.01 & -0.03 & $-0.32 * * *$ & -0.21 & $-0.37 * * *$ & $-0.24 * *$ \\
\hline & & & & & $(0.02)$ & $(0.07)$ & $(0.01)$ & $(0.02)$ & $(0.08)$ & $(0.50)$ & $(0.07)$ & $(0.10)$ \\
\hline Pre-policy period means & & & & & 0.354 & 0.374 & 0.307 & 0.362 & 2.89 & 2.41 & 2.37 & 2.74 \\
\hline $\mathbf{N}$ & & & & & \multicolumn{8}{|c|}{224} \\
\hline
\end{tabular}

Notes: Each column shows findings from a different DD model (Equation 1 in text of paper) estimated using OLS. The dependent variable is the percent of state with the SSI outcome (Panel A) or the percent of state with the worker DI outcome (Panel B). The table shows estimated coefficients and robust standard errors clustered on state. Models are weighted by population in 2000. Models also include: percent in state with college degree, percent in state aged 45-54, percent in state aged 55-64, percent of state unemployed, percent of state living at or below FPL, state fixed effects and year effects estimated coefficients on these covariates are not shown. Data span 2002-2013 for SSI applications and SSI awards, and data span 2000-2013 for all other outcomes. ${ }^{* *}$ indicates statistically significant from zero at the 0.01 level. ** indicates statistically significant from zero at the 0.05 level. * indicates statistically significant from zero at the 0.10 level. 


\begin{tabular}{|c|c|c|c|c|}
\hline State: & CT & DC & CA & $\mathrm{MN}$ \\
\hline & \multicolumn{4}{|c|}{ Panel A: Percent Uninsured Among Low-Income Childless Adults } \\
\hline \multirow[t]{2}{*}{ Treat X Year Implemented } & -0.85 & -2.90 & -0.53 & -0.29 \\
\hline & $(1.21)$ & $(4.22)$ & $(0.87)$ & $(0.62)$ \\
\hline \multirow[t]{2}{*}{ Treat X Post } & -1.21 & -0.87 & -0.27 & -0.64 \\
\hline & $(1.53)$ & $(5.37)$ & (0.99) & $(0.56)$ \\
\hline Pre-policy period means & 29.23 & 14.33 & 44.97 & 26.41 \\
\hline \multirow{2}{*}{$\mathbf{N}$} & \multicolumn{4}{|c|}{96} \\
\hline & \multicolumn{4}{|c|}{ Panel B: Percent with ESHI Among Low-Income Childless Adults } \\
\hline \multirow[t]{2}{*}{ Treat X Year Implemented } & -0.19 & -2.65 & 0.30 & -0.35 \\
\hline & $(0.51)$ & $(1.65)$ & $(0.33)$ & $(0.39)$ \\
\hline \multirow[t]{2}{*}{ Treat X Post } & $-2.35 * * *$ & $-5.83 *$ & 0.52 & 0.11 \\
\hline & $(0.60)$ & $(2.76)$ & $(0.45)$ & $(0.23)$ \\
\hline Pre-policy period means & 31.84 & 38.31 & 21.93 & 32.75 \\
\hline \multirow[t]{2}{*}{$\mathbf{N}$} & \multicolumn{4}{|c|}{96} \\
\hline & \multicolumn{4}{|c|}{ Panel C: Percent with Medicaid Among Low-Income Childless Adults } \\
\hline \multirow[t]{2}{*}{ Treat X Year Implemented } & 0.70 & 0.02 & 0.52 & $1.32^{*}$ \\
\hline & $(1.05)$ & $(4.14)$ & $(0.78)$ & $(0.65)$ \\
\hline \multirow[t]{2}{*}{ Treat X Post } & $4.85 * * *$ & 2.89 & 0.53 & $1.21 * *$ \\
\hline & $(1.43)$ & $(5.11)$ & $(0.86)$ & $(0.50)$ \\
\hline Pre-policy period means & 25.68 & 35.33 & 21.19 & 26.43 \\
\hline \multirow[t]{2}{*}{$\mathbf{N}$} & \multicolumn{4}{|c|}{96} \\
\hline & \multicolumn{4}{|c|}{ Panel D: Percent in fair/poor health } \\
\hline \multirow[t]{2}{*}{ Treat X Year Implemented } & 16.02 & 37.72 & -46.84 & 80.87 \\
\hline & (31.38) & $(151.60)$ & $(47.20)$ & (83.12) \\
\hline \multirow[t]{2}{*}{ Treat X Post } & -59.33 & 26.76 & -28.59 & 72.67 \\
\hline & (62.69) & $(156.74)$ & (35.79) & $(70.60)$ \\
\hline Pre-policy period means & 11.89 & 12.33 & 17.43 & 10.75 \\
\hline \multirow[t]{2}{*}{$\mathbf{N}$} & \multicolumn{4}{|c|}{224} \\
\hline & \multicolumn{4}{|c|}{ Panel E: Total population growth (relative to 2000 population) } \\
\hline \multirow[t]{2}{*}{ Treat X Year Implemented } & -0.03 & -1.55 & 1.41 & $2.87 * * *$ \\
\hline & (1.09) & $(5.85)$ & $(1.08)$ & $(0.96)$ \\
\hline \multirow[t]{2}{*}{ Treat X Post } & 0.10 & 3.18 & $3.11 * * *$ & $3.26 * *$ \\
\hline & $(1.39)$ & $(7.11)$ & $(1.01)$ & $(1.44)$ \\
\hline Pre-policy period means & 103.42 & 102.86 & 106.72 & 105.85 \\
\hline \multirow[t]{2}{*}{$\mathbf{N}$} & \multicolumn{4}{|c|}{224} \\
\hline & \multicolumn{4}{|c|}{$\begin{array}{c}\text { Panel F: Net Migration of Low-Income Childless Adults } \\
\text { (relative to } 2000 \text { population) }\end{array}$} \\
\hline \multirow[t]{2}{*}{ Treat X Year Implemented } & $0.42 * * *$ & $0.97^{* * *}$ & 0.05 & -0.13 \\
\hline & $(0.07)$ & $(0.32)$ & $(0.10)$ & (0.09) \\
\hline Treat X Post & -0.02 & -0.61 & 0.12 & $-0.28 * * *$ \\
\hline
\end{tabular}




\begin{tabular}{ccccc}
\hline & $(0.06)$ & $(0.35)$ & $(0.08)$ & $(0.08)$ \\
Pre-policy period means & -0.03 & 1.25 & 0.28 & 0.02 \\
$\mathbf{N}$ & \multicolumn{2}{c}{224} \\
\hline
\end{tabular}

Notes: The sample is childless adults aged 18-64 with family income below 200 percent of FPL for Panels A, B, and C, adults aged 18 and older for Panel D, and adults aged 18-64 for Panel E. In Panel F, population growth is calculated as net migration of childless adults aged 18-64 with family income below 200 percent of FPL divided by total population in 2000 multiplied by 100 . Each column in each panel shows findings from a different DD model (Equation 1) estimated using OLS. The table shows estimated coefficients and robust standard errors clustered on state. Models include state fixed effects and year effects, and the covariates shown in the notes to Table 2 - estimated coefficients on these covariates are not shown. Data span 2008-2013 for Panels A-C and 2000-2013 for Panels D-F. *** indicates statistically significant from zero at the 0.01 level. ** indicates statistically significant from zero at the 0.05 level. * indicates statistically significant from zero at the 0.10 level. 


\begin{tabular}{cccccc}
\hline \multicolumn{5}{c}{ Table 4: Synthetic Control Weights -- CT } \\
\hline Arkansas & Spl & & & \multicolumn{3}{c}{ DI } \\
\hline Illinois & 0.000 & 0.000 & 0.000 & 0.000 & 0.000 \\
lowa & 0.000 & 0.000 & 0.000 & 0.000 & 0.000 \\
Kentucky & 0.000 & 0.108 & 0.000 & 0.000 & 0.000 \\
Maryland & 0.000 & 0.000 & 0.000 & 0.000 & 0.000 \\
Nevada & 0.425 & 0.000 & 0.000 & 0.565 & 0.000 \\
New Jersey & 0.000 & 0.000 & 0.015 & 0.000 & 0.000 \\
\hline New Mexico & 0.535 & 0.880 & 0.759 & 0.261 & 0.919 \\
\hline North Dakota & 0.000 & 0.000 & 0.000 & 0.000 & 0.000 \\
Ohio & 0.000 & 0.000 & 0.000 & 0.000 & 0.000 \\
Oregon & 0.000 & 0.000 & 0.000 & 0.000 & 0.000 \\
Rhode Island & 0.000 & 0.007 & 0.226 & 0.174 & 0.041 \\
Washington & 0.000 & 0.000 & 0.000 & 0.000 & 0.000 \\
\hline West Virginia & 0.040 & 0.005 & 0.000 & 0.000 & 0.040 \\
Wisconsin & 0.000 & 0.000 & 0.000 & 0.000 & 0.000 \\
\hline
\end{tabular}


Table 5: Matching on pre-policy covariates in CT - Synthetic control vs. average of control states

\begin{tabular}{|c|c|c|c|c|c|c|c|c|c|}
\hline \multirow[t]{2}{*}{ Panel A: SSI Outcomes } & \multicolumn{2}{|c|}{ SSI applications } & \multirow[b]{2}{*}{$\begin{array}{c}\text { Synthetic } \\
\text { Control }\end{array}$} & \multicolumn{2}{|c|}{ SSI awards } & \multicolumn{4}{|c|}{ SSI recipients } \\
\hline & $\mathrm{CT}$ & $\begin{array}{c}\text { Average of } \\
\text { Controls }\end{array}$ & & $\mathrm{CT}$ & $\begin{array}{c}\text { Average } \\
\text { of } \\
\text { Controls }\end{array}$ & $\begin{array}{l}\text { Synthetic } \\
\text { Control }\end{array}$ & $\mathrm{CT}$ & $\begin{array}{c}\text { Average } \\
\text { of } \\
\text { Controls }\end{array}$ & $\begin{array}{c}\text { Synthetic } \\
\text { Control }\end{array}$ \\
\hline$\%$ with college degree & 0.375 & 0.292 & 0.361 & 0.375 & 0.292 & 0.355 & 0.373 & 0.288 & 0.345 \\
\hline$\%$ aged 45-54 & 0.249 & 0.236 & 0.241 & 0.249 & 0.236 & 0.242 & 0.248 & 0.235 & 0.239 \\
\hline$\%$ aged 55-64 & 0.178 & 0.171 & 0.171 & 0.178 & 0.171 & 0.171 & 0.173 & 0.166 & 0.168 \\
\hline$\%$ unemployed & 0.064 & 0.070 & 0.064 & 0.064 & 0.070 & 0.067 & 0.061 & 0.067 & 0.068 \\
\hline$\%$ living in poverty & 0.091 & 0.123 & 0.089 & 0.091 & 0.123 & 0.088 & 0.0857 & 0.119 & 0.094 \\
\hline outcome variable & 0.788 & 1.009 & 0.788 & 0.224 & 0.299 & 0.226 & 1.530 & 2.166 & 1.532 \\
\hline \multirow[t]{2}{*}{ Panel B: DI Outcomes } & & & & \multicolumn{2}{|c|}{ DI awards } & \multicolumn{4}{|c|}{ DI recipients } \\
\hline & & & & $\mathrm{CT}$ & $\begin{array}{c}\text { Average } \\
\text { of } \\
\text { Controls }\end{array}$ & $\begin{array}{l}\text { Synthetic } \\
\text { Control }\end{array}$ & $\mathrm{CT}$ & $\begin{array}{c}\text { Average } \\
\text { of } \\
\text { Controls }\end{array}$ & $\begin{array}{c}\text { Synthetic } \\
\text { Control }\end{array}$ \\
\hline$\%$ with college degree & & & & 0.373 & 0.288 & 0.352 & 0.373 & 0.288 & 0.354 \\
\hline$\%$ aged $45-54$ & & & & 0.248 & 0.235 & 0.239 & 0.248 & 0.235 & 0.240 \\
\hline$\%$ aged $55-64$ & & & & 0.173 & 0.166 & 0.166 & 0.172 & 0.166 & 0.168 \\
\hline$\%$ unemployed & & & & 0.061 & 0.067 & 0.061 & 0.061 & 0.067 & 0.067 \\
\hline$\%$ living in poverty & & & & 0.086 & 0.119 & 0.092 & 0.086 & 0.119 & 0.087 \\
\hline outcome variable & & & & 0.354 & 0.419 & 0.358 & 2.894 & 3.306 & 2.896 \\
\hline
\end{tabular}

Notes: Each covariate is the average of that variable during the pre-policy period for CT. The pre-policy period is $2002-2009$ for the SSI applications and SSI awards outcomes, and 2000-2009 for the other three outcomes. The controls are the 15 states that expanded Medicaid on 1/1/14: AR, IL, IA, KY, MD, $\mathrm{NV}, \mathrm{NJ}, \mathrm{NM}, \mathrm{ND}, \mathrm{OH}, \mathrm{OR}, \mathrm{RI}, \mathrm{WA}, \mathrm{WV}$ and WI. The synthetic control is weighted combination of the 15 control states, with the weights shown in Table 4. 


\begin{tabular}{|c|c|c|c|c|}
\hline & (1) & $(2)$ & (3) & (4) \\
\hline & CT & DC & CA & MN \\
\hline SSI applications & $\begin{array}{c}-0.065 \\
(0.875)\end{array}$ & $\begin{array}{c}-0.051 \\
(0.875)\end{array}$ & $\begin{array}{c}-0.011 \\
(0.938)\end{array}$ & $\begin{array}{c}0.033 \\
(0.688)\end{array}$ \\
\hline SSI awards & $\begin{array}{c}-0.030 \\
(0.500)\end{array}$ & $\begin{array}{c}0.098 \\
(0.188)\end{array}$ & $\begin{array}{c}-0.013 \\
(0.688)\end{array}$ & $\begin{array}{c}0.022 \\
(0.375)\end{array}$ \\
\hline SSI recipients & $\begin{array}{l}-0.111^{*} \\
(0.063)\end{array}$ & $\begin{array}{c}0.500 \\
(0.438)\end{array}$ & $\begin{array}{c}-0.163 \\
(0.625)\end{array}$ & $\begin{array}{c}0.237 \\
(0.438)\end{array}$ \\
\hline DI awards & $\begin{array}{c}-0.062 \\
(0.188)\end{array}$ & $\begin{array}{l}-0.004 \\
(1.00)\end{array}$ & $\begin{array}{c}-0.055 \\
(0.375)\end{array}$ & $\begin{array}{c}-0.007 \\
(0.750)\end{array}$ \\
\hline DI recipients & $\begin{array}{l}-0.166 \\
(0.375) \\
\end{array}$ & $\begin{array}{c}-0.212 \\
(0.313) \\
\end{array}$ & $\begin{array}{c}-0.471 \\
(0.188) \\
\end{array}$ & $\begin{array}{l}0.004 \\
(1.00) \\
\end{array}$ \\
\hline
\end{tabular}

Notes: Table reports estimates of the average post-policy differences in each outcome between the treated state and the synthetic control states. The $p$-value is in parentheses. The $p$-value is calculated based on the ratio of the MSPE in the post-policy period vs. the MSPE in the pre-policy period for each treated state and for each state in the donor pool when it is falsely assigned as the treated state. The p-value is the number of states with a MSPE at least as high as the true treated state plus one (for the treated state) divided by 16 , which is the number of donor states plus the treated state. * indicates statistically significant from zero at the 0.10 level. 
Figure 1: Synthetic control estimates of effects of Medicaid expansion on SSI applications
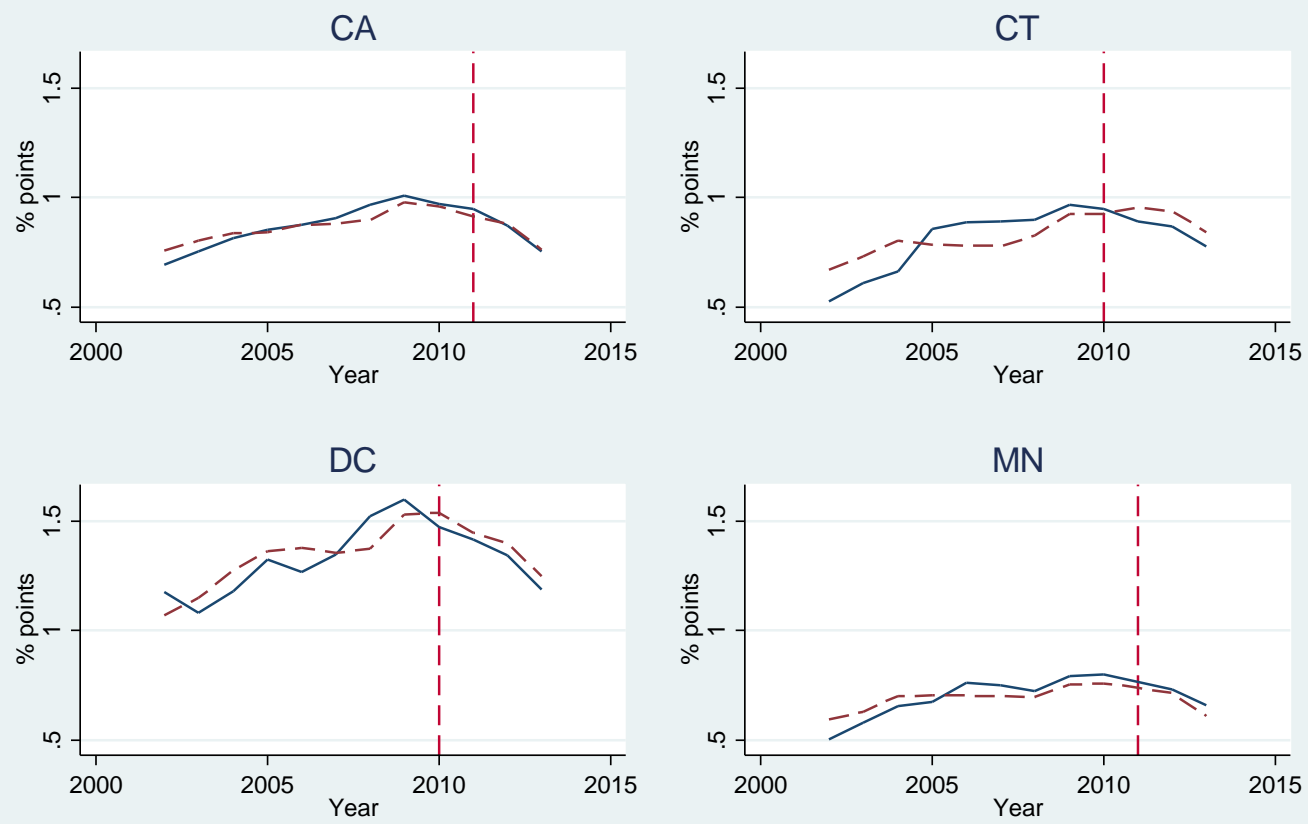

Treated - - - - Synthetic control

Figure 2: Synthetic control estimates of effects of Medicaid expansion on SSI awards
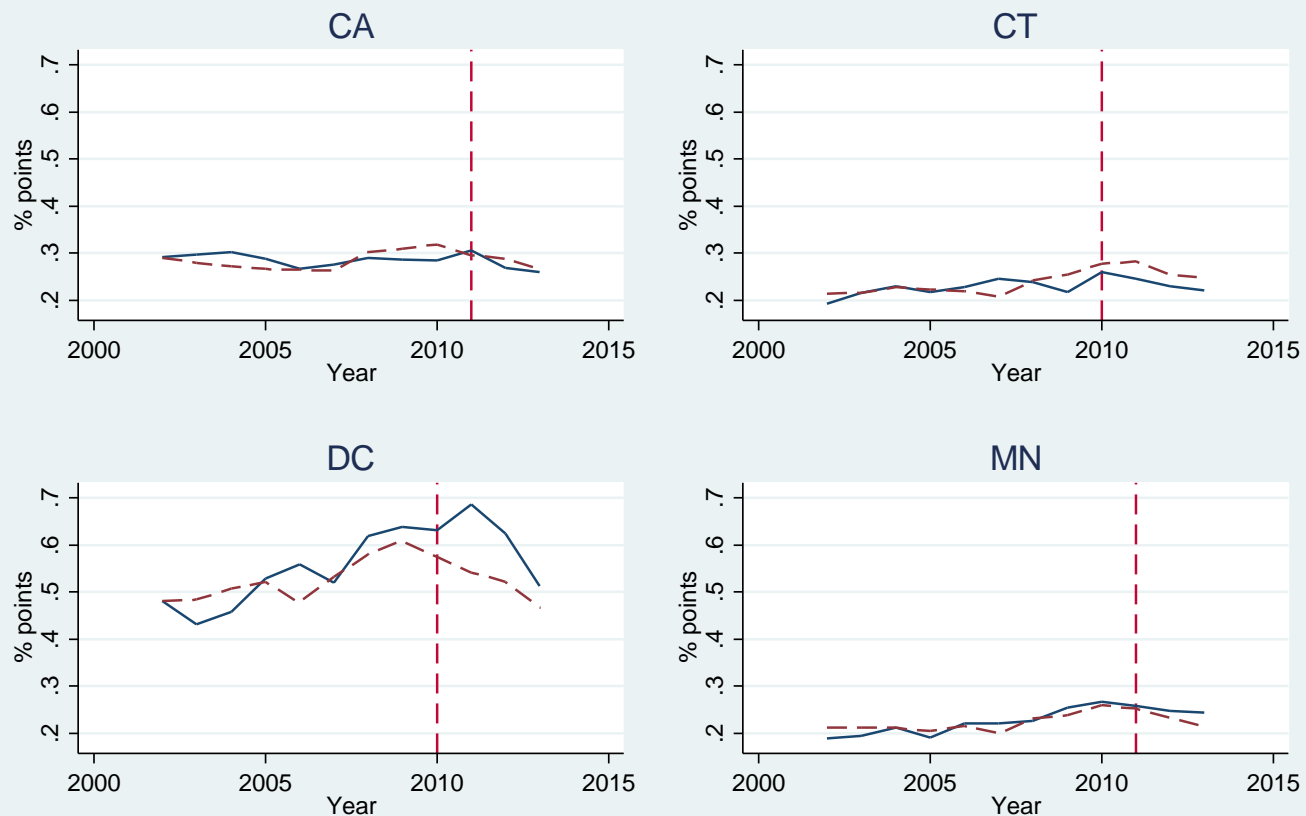

Treated ----- Synthetic control 
Figure 3: Synthetic control estimates of effects of Medicaid expansion on SSI recipients
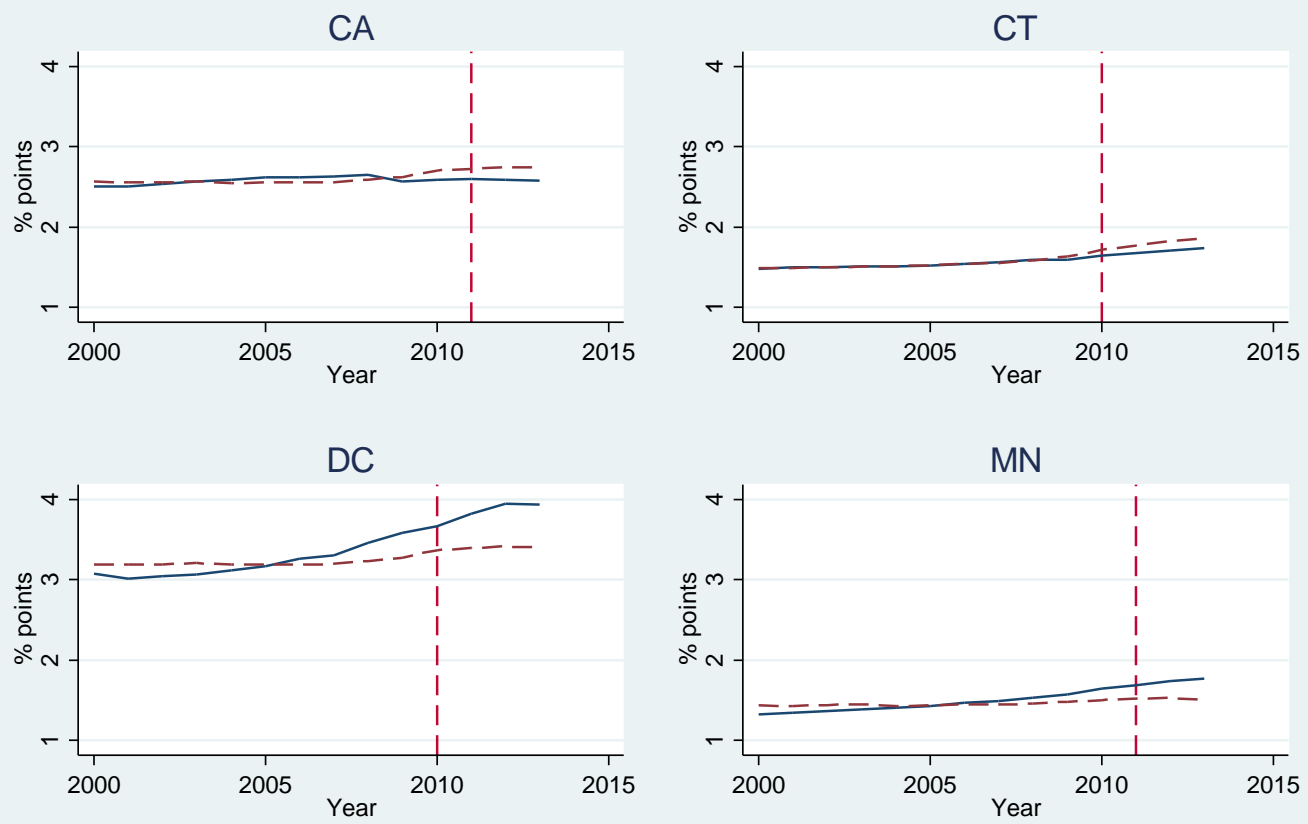

Treated - - - - Synthetic control

Figure 4: Synthetic control estimates of effects of Medicaid expansion on DI awards
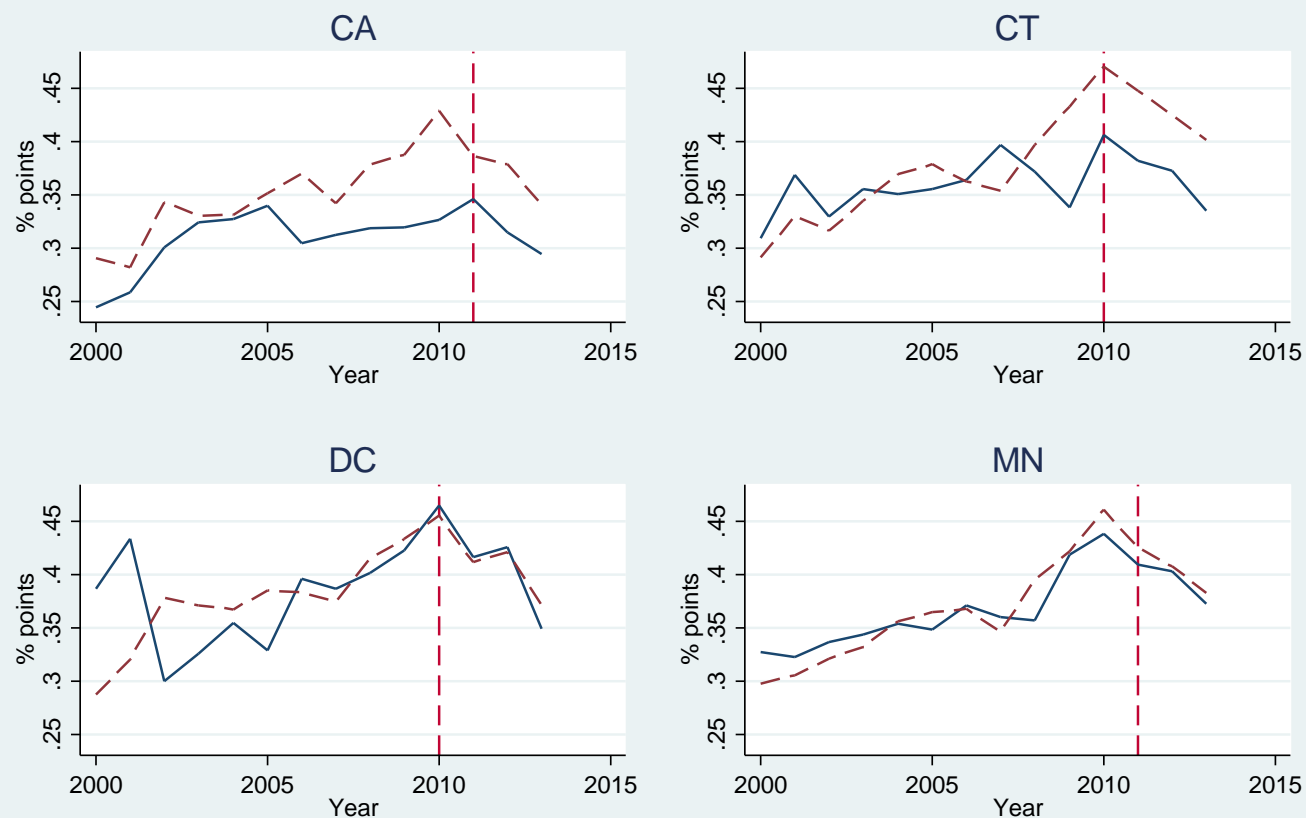

Treated ----- Synthetic control 
Figure 5: Synthetic control estimates of effects of Medicaid expansion on DI recipients
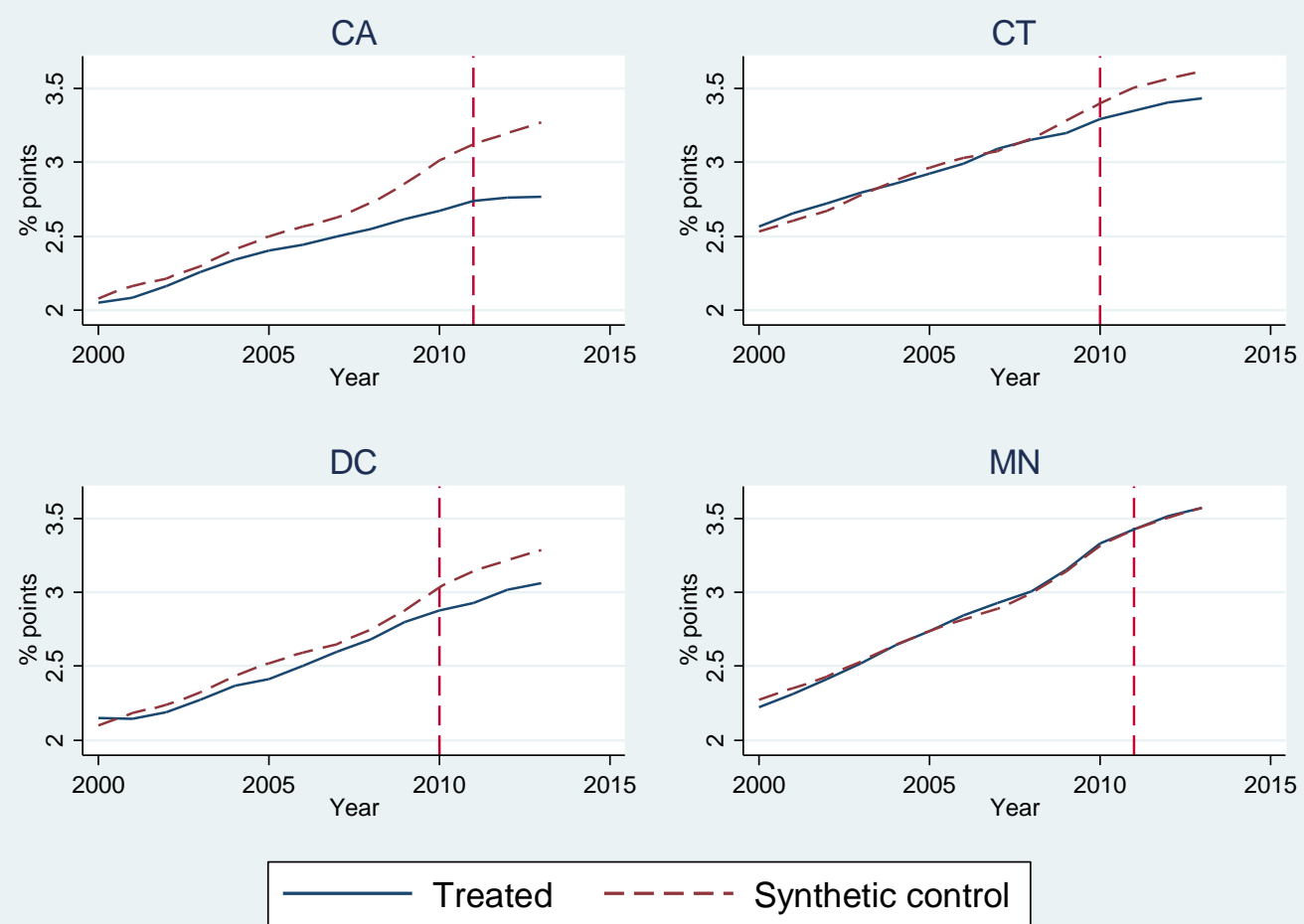


\begin{tabular}{|c|c|c|c|c|c|}
\hline \multicolumn{6}{|c|}{ Appendix Table 1: Synthetic Control Weights -- DC } \\
\hline & \multicolumn{3}{|c|}{$\underline{\mathrm{SSI}}$} & \multicolumn{2}{|c|}{$\underline{\mathrm{DI}}$} \\
\hline & Applications & Awards & Recipients & Awards & Recipients \\
\hline Arkansas & 0.308 & 0.900 & 0.000 & 0.056 & 0.000 \\
\hline Illinois & 0.255 & 0.100 & 0.519 & 0.944 & 0.101 \\
\hline lowa & 0.000 & 0.000 & 0.000 & 0.000 & 0.000 \\
\hline Kentucky & 0.123 & 0.000 & 0.481 & 0.000 & 0.000 \\
\hline Maryland & 0.000 & 0.000 & 0.000 & 0.000 & 0.899 \\
\hline Nevada & 0.000 & 0.000 & 0.000 & 0.000 & 0.000 \\
\hline New Jersey & 0.000 & 0.000 & 0.000 & 0.000 & 0.000 \\
\hline New Mexico & 0.314 & 0.000 & 0.000 & 0.000 & 0.000 \\
\hline North Dakota & 0.000 & 0.000 & 0.000 & 0.000 & 0.000 \\
\hline Ohio & 0.000 & 0.000 & 0.000 & 0.000 & 0.000 \\
\hline Oregon & 0.000 & 0.000 & 0.000 & 0.000 & 0.000 \\
\hline Rhode Island & 0.000 & 0.000 & 0.000 & 0.000 & 0.000 \\
\hline Washington & 0.000 & 0.000 & 0.000 & 0.000 & 0.000 \\
\hline West Virginia & 0.000 & 0.000 & 0.000 & 0.000 & 0.000 \\
\hline Wisconsin & 0.000 & 0.000 & 0.000 & 0.000 & 0.000 \\
\hline
\end{tabular}

\begin{tabular}{lrrrrr}
\hline \multicolumn{5}{c}{ Appendix Table 2: Synthetic Control Weights -- CA } \\
\hline & \multicolumn{3}{c}{ SSI } & & \multicolumn{3}{c}{ DI } \\
\hline Arkansas & 0.000 & 0.111 & 0.000 & 0.000 & 0.000 \\
\hline Illinois & 0.882 & 0.641 & 0.769 & 0.672 & 0.000 \\
lowa & 0.000 & 0.000 & 0.000 & 0.000 & 0.000 \\
Kentucky & 0.000 & 0.000 & 0.231 & 0.000 & 0.000 \\
Maryland & 0.000 & 0.000 & 0.000 & 0.000 & 1.000 \\
Nevada & 0.074 & 0.248 & 0.000 & 0.000 & 0.000 \\
New Jersey & 0.000 & 0.000 & 0.000 & 0.000 & 0.000 \\
New Mexico & 0.043 & 0.000 & 0.000 & 0.000 & 0.000 \\
North Dakota & 0.000 & 0.000 & 0.000 & 0.328 & 0.000 \\
\hline Ohio & 0.000 & 0.000 & 0.000 & 0.000 & 0.000 \\
Oregon & 0.000 & 0.000 & 0.000 & 0.000 & 0.000 \\
Rhode Island & 0.000 & 0.000 & 0.000 & 0.000 & 0.000 \\
Washington & 0.000 & 0.000 & 0.000 & 0.000 & 0.000 \\
West Virginia & 0.000 & 0.000 & 0.000 & 0.000 & 0.000 \\
Wisconsin & 0.000 & 0.000 & 0.000 & 0.000 & 0.000 \\
\hline
\end{tabular}




\begin{tabular}{lccccc}
\hline \multicolumn{5}{c}{ Appendix Table 3: Synthetic Control Weights -- MN } \\
\hline & & SSI & & \multicolumn{2}{c}{ DI } \\
Arkansas & 0.000 & 0.000 & 0.000 & 0.000 & 0.000 \\
Illinois & 0.097 & 0.175 & 0.152 & 0.190 & 0.244 \\
lowa & 0.000 & 0.000 & 0.000 & 0.000 & 0.000 \\
Kentucky & 0.000 & 0.000 & 0.000 & 0.000 & 0.000 \\
Maryland & 0.009 & 0.027 & 0.000 & 0.534 & 0.545 \\
Nevada & 0.000 & 0.000 & 0.000 & 0.000 & 0.000 \\
New Jersey & 0.577 & 0.427 & 0.195 & 0.000 & 0.000 \\
New Mexico & 0.000 & 0.000 & 0.000 & 0.000 & 0.000 \\
North Dakota & 0.317 & 0.372 & 0.652 & 0.136 & 0.000 \\
Ohio & 0.000 & 0.000 & 0.000 & 0.000 & 0.000 \\
Oregon & 0.000 & 0.000 & 0.000 & 0.000 & 0.000 \\
Rhode Island & 0.000 & 0.000 & 0.000 & 0.000 & 0.047 \\
Washington & 0.000 & 0.000 & 0.000 & 0.000 & 0.000 \\
West Virginia & 0.000 & 0.000 & 0.000 & 0.000 & 0.000 \\
Wisconsin & 0.000 & 0.000 & 0.000 & 0.140 & 0.165 \\
\hline
\end{tabular}




\begin{tabular}{|c|c|c|c|c|c|c|c|c|c|}
\hline \multirow[t]{2}{*}{ Panel A: SSI Outcomes } & \multicolumn{3}{|c|}{ SSI applications } & \multicolumn{3}{|c|}{ SSI awards } & \multicolumn{3}{|c|}{ SSI recipients } \\
\hline & DC & $\begin{array}{c}\text { Average } \\
\text { of } \\
\text { Controls }\end{array}$ & $\begin{array}{c}\text { Synthetic } \\
\text { Control }\end{array}$ & $\mathrm{DC}$ & $\begin{array}{c}\text { Average } \\
\text { of } \\
\text { Controls }\end{array}$ & $\begin{array}{c}\text { Synthetic } \\
\text { Control }\end{array}$ & DC & $\begin{array}{c}\text { Average } \\
\text { of } \\
\text { Controls }\end{array}$ & $\begin{array}{c}\text { Synthetic } \\
\text { Control }\end{array}$ \\
\hline$\%$ with college degree & 0.493 & 0.292 & 0.251 & 0.493 & 0.292 & 0.215 & 0.483 & 0.288 & 0.263 \\
\hline$\%$ aged $45-54$ & 0.195 & 0.236 & 0.228 & 0.195 & 0.236 & 0.226 & 0.199 & 0.235 & 0.230 \\
\hline$\%$ aged $55-64$ & 0.154 & 0.171 & 0.173 & 0.154 & 0.171 & 0.178 & 0.152 & 0.166 & 0.163 \\
\hline$\%$ unemployed & 0.092 & 0.070 & 0.073 & 0.092 & 0.070 & 0.073 & 0.089 & 0.067 & 0.073 \\
\hline$\%$ living in poverty & 0.181 & 0.123 & 0.157 & 0.181 & 0.123 & 0.160 & 0.174 & 0.119 & 0.140 \\
\hline outcome variable & 1.312 & 1.009 & 1.311 & 0.529 & 0.299 & 0.524 & 3.210 & 2.166 & 3.205 \\
\hline \multicolumn{4}{|l|}{ Panel B: DI Outcomes } & \multicolumn{2}{|c|}{ DI awards } & \multicolumn{4}{|c|}{ DI recipients } \\
\hline & & & & $\mathrm{DC}$ & $\begin{array}{c}\text { Average } \\
\text { of } \\
\text { Controls }\end{array}$ & $\begin{array}{c}\text { Synthetic } \\
\text { Control }\end{array}$ & DC & $\begin{array}{c}\text { Average } \\
\text { of } \\
\text { Controls }\end{array}$ & $\begin{array}{c}\text { Synthetic } \\
\text { Control }\end{array}$ \\
\hline$\%$ with college degree & & & & 0.483 & 0.288 & 0.309 & 0.483 & 0.288 & 0.361 \\
\hline$\%$ aged $45-54$ & & & & 0.199 & 0.235 & 0.227 & 0.199 & 0.235 & 0.237 \\
\hline$\%$ aged $55-64$ & & & & 0.152 & 0.166 & 0.157 & 0.152 & 0.166 & 0.163 \\
\hline$\%$ unemployed & & & & 0.089 & 0.067 & 0.074 & 0.089 & 0.067 & 0.057 \\
\hline \% living in poverty & & & & 0.174 & 0.119 & 0.118 & 0.174 & 0.119 & 0.087 \\
\hline outcome variable & & & & 0.374 & 0.419 & 0.372 & 2.412 & 3.306 & 2.467 \\
\hline
\end{tabular}

Notes: Each covariate is the average of that variable during the pre-policy period for DC. The pre-policy period is $2002-2009$ for the SSI applications and SSI awards outcomes, and 2000-2009 for the other three outcomes. The controls are the 15 states that expanded Medicaid on 1/1/14: AR, IL, IA, KY, MD, $\mathrm{NV}, \mathrm{NJ}, \mathrm{NM}, \mathrm{ND}, \mathrm{OH}, \mathrm{OR}, \mathrm{RI}, \mathrm{WA}, \mathrm{WV}$ and WI. The synthetic control is weighted combination of the 15 control states, with the weights shown in Appendix Table 1. 
Appendix Table 5: Matching on pre-policy covariates in CA - Synthetic Control vs. Average of Control States

\begin{tabular}{|c|c|c|c|c|c|c|c|c|c|}
\hline \multicolumn{4}{|c|}{ SSI applications } & \multicolumn{3}{|c|}{ SSI awards } & \multicolumn{3}{|c|}{ SSI recipients } \\
\hline Panel A: SSI Outcomes & CA & $\begin{array}{l}\text { Average of } \\
\text { Controls }\end{array}$ & $\begin{array}{c}\text { Synthetic } \\
\text { Control }\end{array}$ & $\mathrm{CA}$ & $\begin{array}{l}\text { Average } \\
\text { of } \\
\text { Controls }\end{array}$ & $\begin{array}{c}\text { Synthetic } \\
\text { Control }\end{array}$ & $\mathrm{CA}$ & $\begin{array}{l}\text { Average } \\
\text { of } \\
\text { Controls }\end{array}$ & $\begin{array}{c}\text { Synthetic } \\
\text { Control }\end{array}$ \\
\hline$\%$ with college degree & 0.305 & 0.293 & 0.309 & 0.305 & 0.293 & 0.281 & 0.302 & 0.290 & 0.292 \\
\hline$\%$ aged $45-54$ & 0.219 & 0.236 & 0.228 & 0.219 & 0.236 & 0.225 & 0.218 & 0.235 & 0.229 \\
\hline$\%$ aged 55-64 & 0.152 & 0.174 & 0.164 & 0.152 & 0.174 & 0.167 & 0.148 & 0.169 & 0.161 \\
\hline$\%$ unemployed & 0.082 & 0.074 & 0.081 & 0.082 & 0.074 & 0.080 & 0.078 & 0.071 & 0.077 \\
\hline \% living in poverty & 0.134 & 0.127 & 0.125 & 0.134 & 0.127 & 0.126 & 0.131 & 0.122 & 0.130 \\
\hline \multirow[t]{2}{*}{ outcome variable } & 0.871 & 1.028 & 0.871 & 0.287 & 0.308 & 0.286 & 2.582 & 2.187 & 2.580 \\
\hline & & & & \multicolumn{2}{|c|}{ DI awards } & \multicolumn{4}{|c|}{ DI recipients } \\
\hline Panel B: DI Outcomes & & & & $\mathrm{CA}$ & $\begin{array}{c}\text { Average } \\
\text { of } \\
\text { Controls }\end{array}$ & $\begin{array}{c}\text { Synthetic } \\
\text { Control }\end{array}$ & $\mathrm{CA}$ & $\begin{array}{c}\text { Average } \\
\text { of } \\
\text { Controls }\end{array}$ & $\begin{array}{c}\text { Synthetic } \\
\text { Control }\end{array}$ \\
\hline$\%$ with college degree & & & & 0.302 & 0.290 & 0.308 & 0.302 & 0.290 & 0.367 \\
\hline$\%$ aged $45-54$ & & & & 0.218 & 0.235 & 0.230 & 0.218 & 0.235 & 0.239 \\
\hline$\%$ aged $55-64$ & & & & 0.148 & 0.169 & 0.161 & 0.148 & 0.169 & 0.166 \\
\hline$\%$ unemployed & & & & 0.078 & 0.071 & 0.064 & 0.078 & 0.071 & 0.058 \\
\hline$\%$ living in poverty & & & & 0.131 & 0.122 & 0.121 & 0.131 & 0.122 & 0.087 \\
\hline outcome variable & & & & 0.307 & 0.430 & 0.349 & 2.370 & 3.374 & 2.495 \\
\hline
\end{tabular}

Notes: Each covariate is the average of that variable during the pre-policy period for CA. The pre-policy period is 2002-2010 for the SSI applications and SSI awards outcomes, and 2000-2009 for the other three outcomes. The controls are the 15 states that expanded Medicaid on 1/1/14: AR, IL, IA, KY, MD, $\mathrm{NV}, \mathrm{NJ}, \mathrm{NM}, \mathrm{ND}, \mathrm{OH}, \mathrm{OR}, \mathrm{RI}, \mathrm{WA}, \mathrm{WV}$ and WI. The synthetic control is weighted combination of the 15 control states, with the weights shown in Appendix Table 2 . 


\begin{tabular}{|c|c|c|c|c|c|c|c|c|c|}
\hline \multicolumn{4}{|c|}{ SSI applications } & \multicolumn{3}{|c|}{ SSI awards } & \multicolumn{3}{|c|}{ SSI recipients } \\
\hline Panel A: SSI Outcomes & $\mathrm{MN}$ & $\begin{array}{c}\text { Average of } \\
\text { Controls }\end{array}$ & $\begin{array}{c}\text { Synthetic } \\
\text { Control }\end{array}$ & $\mathrm{MN}$ & $\begin{array}{c}\text { Average } \\
\text { of } \\
\text { Controls }\end{array}$ & $\begin{array}{c}\text { Synthetic } \\
\text { Control }\end{array}$ & $\mathrm{MN}$ & $\begin{array}{c}\text { Average } \\
\text { of } \\
\text { Controls }\end{array}$ & $\begin{array}{c}\text { Synthetic } \\
\text { Control }\end{array}$ \\
\hline$\%$ with college degree & 0.336 & 0.293 & 0.341 & 0.336 & 0.293 & 0.334 & 0.331 & 0.290 & 0.309 \\
\hline$\%$ aged $45-54$ & 0.241 & 0.236 & 0.240 & 0.241 & 0.236 & 0.238 & 0.238 & 0.235 & 0.235 \\
\hline$\%$ aged $55-64$ & 0.166 & 0.174 & 0.172 & 0.166 & 0.174 & 0.171 & 0.160 & 0.169 & 0.165 \\
\hline$\%$ unemployed & 0.058 & 0.074 & 0.062 & 0.058 & 0.074 & 0.061 & 0.054 & 0.071 & 0.049 \\
\hline \% living in poverty & 0.099 & 0.127 & 0.103 & 0.099 & 0.127 & 0.109 & 0.093 & 0.122 & 0.116 \\
\hline \multirow[t]{2}{*}{ outcome variable } & 0.694 & 1.028 & 0.694 & 0.220 & 0.308 & 0.221 & 1.448 & 2.187 & 1.448 \\
\hline & & & & \multicolumn{2}{|c|}{ DI awards } & \multicolumn{4}{|c|}{ DI recipients } \\
\hline Panel B: DI Outcomes & & & & MN & $\begin{array}{c}\text { Average } \\
\text { of } \\
\text { Controls }\end{array}$ & $\begin{array}{c}\text { Synthetic } \\
\text { Control }\end{array}$ & $\mathrm{MN}$ & $\begin{array}{c}\text { Average } \\
\text { of } \\
\text { Controls }\end{array}$ & $\begin{array}{c}\text { Synthetic } \\
\text { Control }\end{array}$ \\
\hline$\%$ with college degree & & & & 0.331 & 0.290 & 0.333 & 0.331 & 0.290 & 0.337 \\
\hline$\%$ aged $45-54$ & & & & 0.238 & 0.235 & 0.236 & 0.238 & 0.235 & 0.237 \\
\hline$\%$ aged 55-64 & & & & 0.160 & 0.169 & 0.165 & 0.160 & 0.169 & 0.165 \\
\hline$\%$ unemployed & & & & 0.054 & 0.071 & 0.059 & 0.054 & 0.071 & 0.064 \\
\hline \% living in poverty & & & & 0.093 & 0.122 & 0.102 & 0.093 & 0.122 & 0.100 \\
\hline outcome variable & & & & 0.362 & 0.430 & 0.361 & 2.737 & 3.374 & 2.739 \\
\hline
\end{tabular}

Notes: Each covariate is the average of that variable during the pre-policy period for MN. The pre-policy period is $2002-2010$ for the SSI applications and SSI awards outcomes, and 2000-2009 for the other three outcomes. The controls are the 15 states that expanded Medicaid on 1/1/14: AR, IL, IA, KY, MD, $\mathrm{NV}, \mathrm{NJ}, \mathrm{NM}, \mathrm{ND}, \mathrm{OH}, \mathrm{OR}, \mathrm{RI}, \mathrm{WA}, \mathrm{WV}$ and WI. The synthetic control is weighted combination of the 15 control states, with the weights shown in Appendix Table 3 . 
Appendix Figure 1: Pre and post Medicaid expansion trends in SSI applications
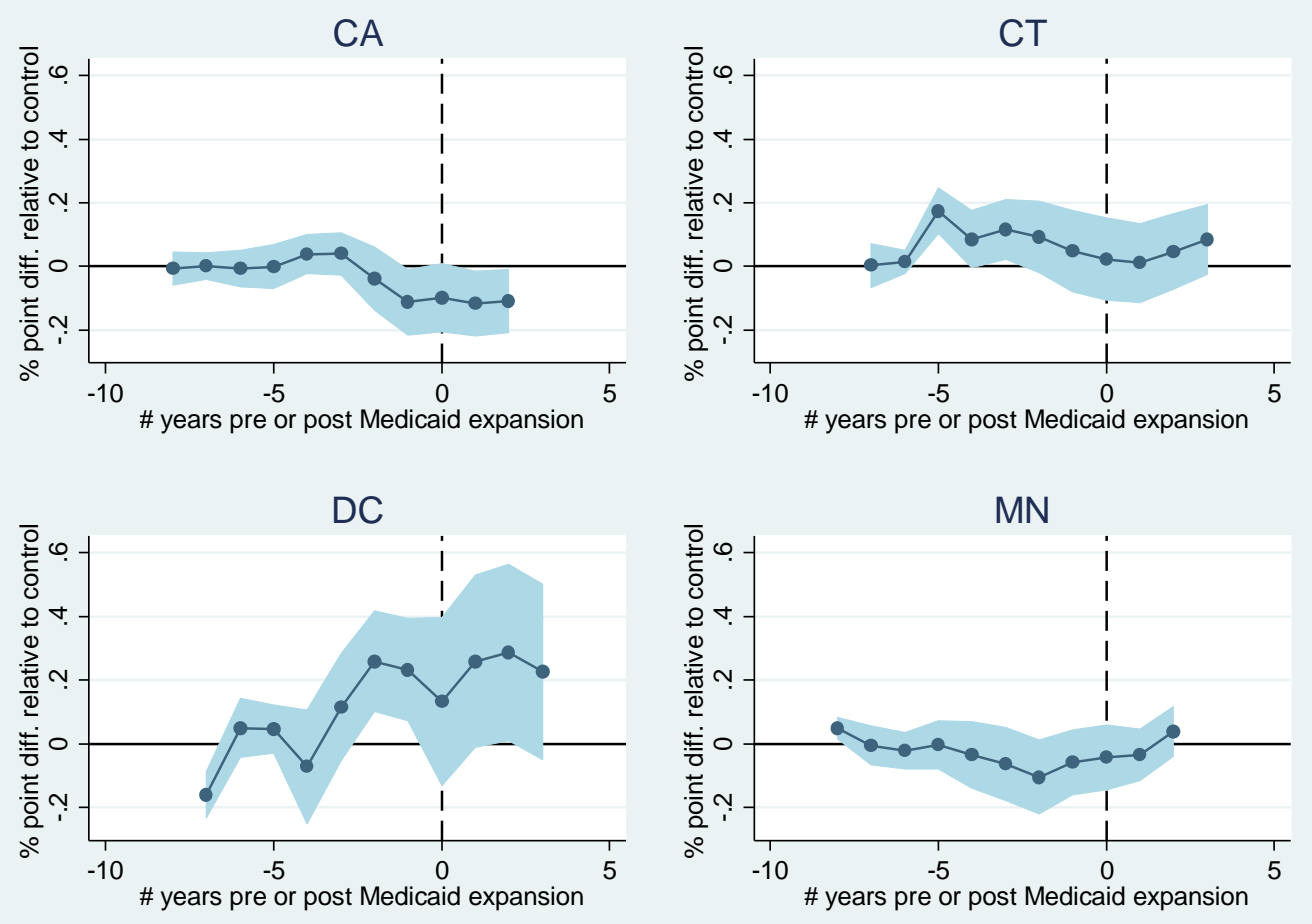

Notes: Figures generated using Equation 2 in text. Blue shading represents 95\% CI for estimates.

Appendix Figure 2: Pre and post Medicaid expansion trends in SSI awards
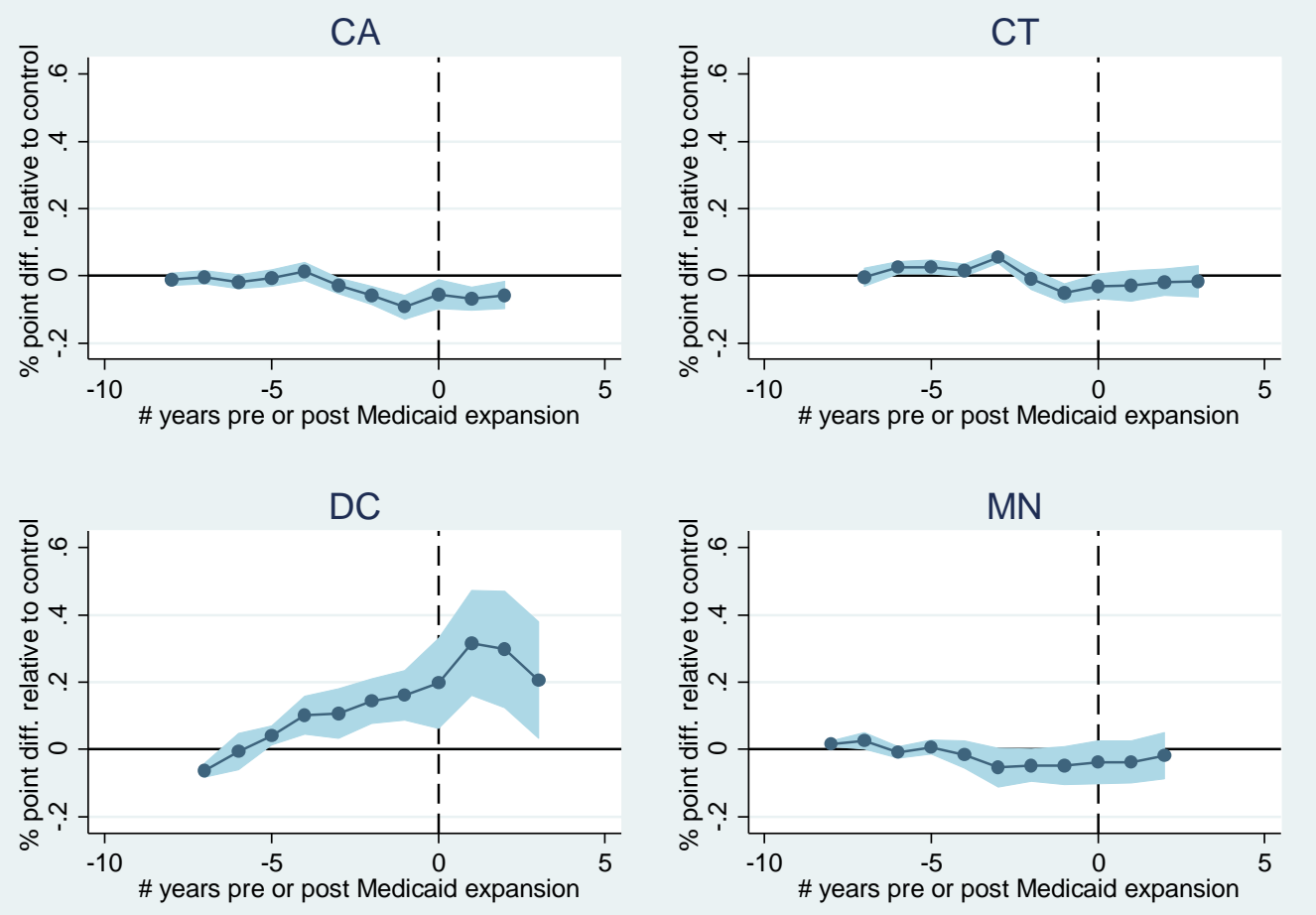

Notes: Figures generated using Equation 2 in text. Blue shading represents 95\% CI for estimates. 
Appendix Figure 3: Pre and post Medicaid expansion trends in SSI recipients
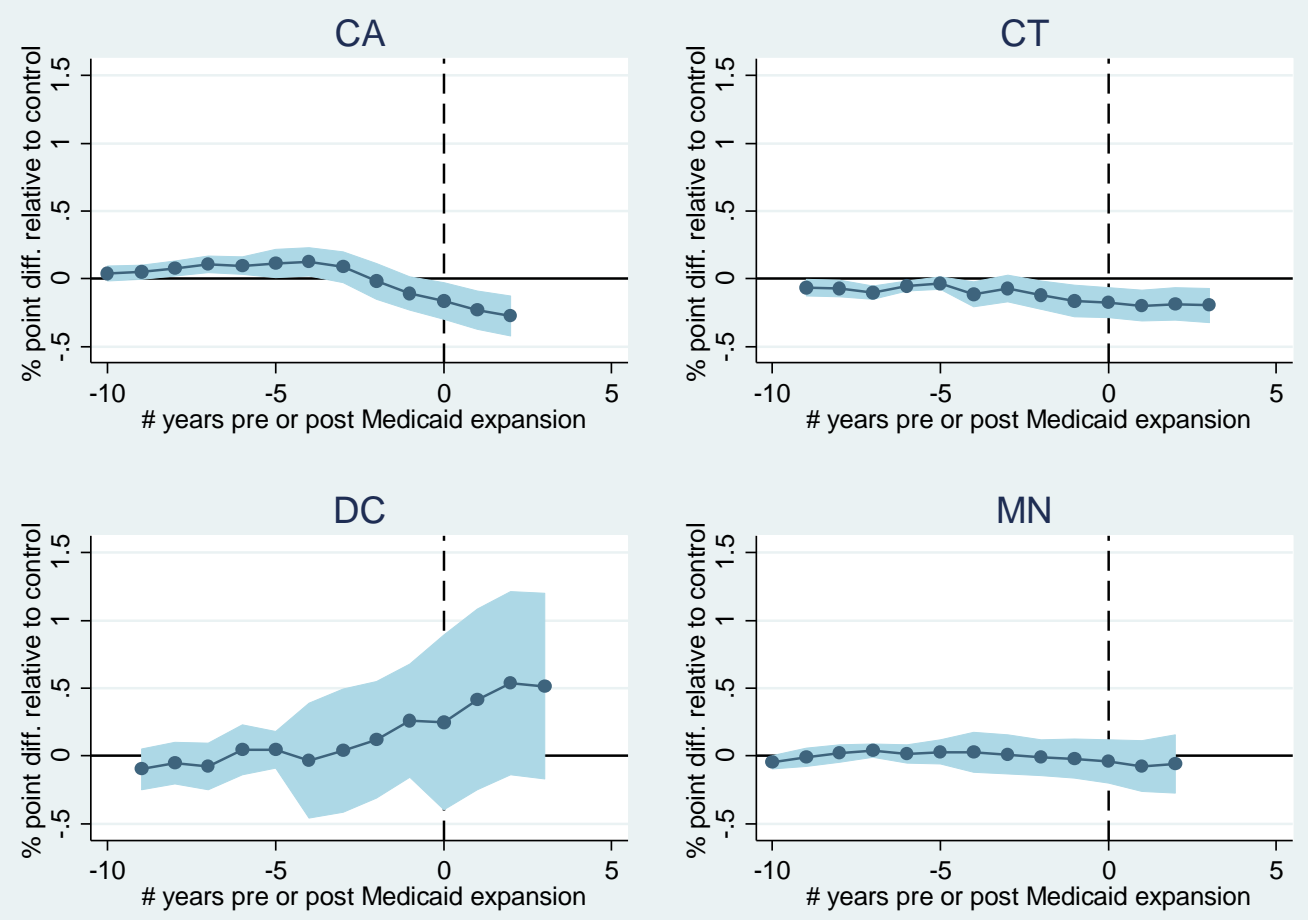

Notes: Figures generated using Equation 2 in text. Blue shading represents 95\% CI for estimates.

Appendix Figure 4: Pre and post Medicaid expansion trends in DI awards
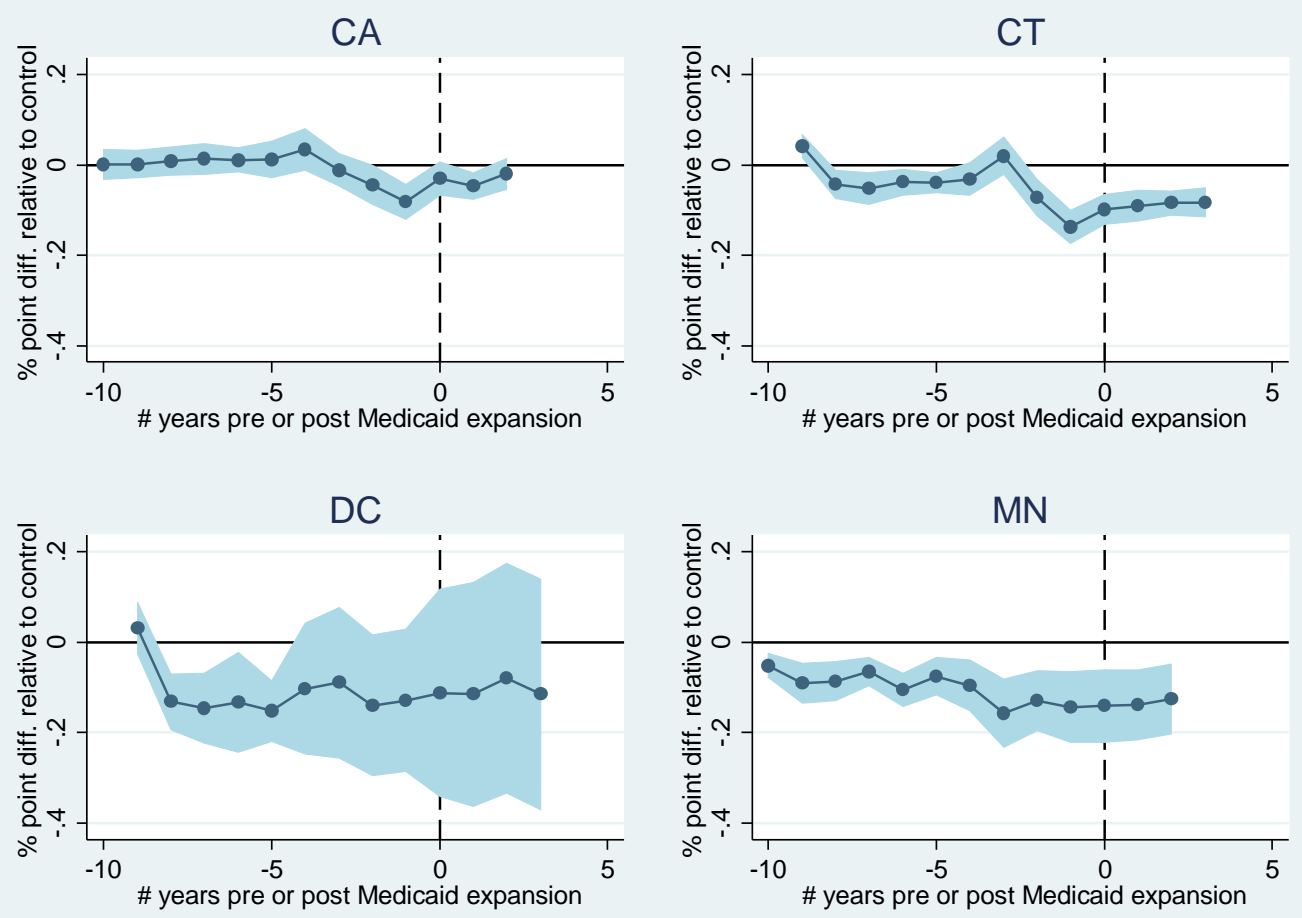

Notes: Figures generated using Equation 2 in text. Blue shading represents 95\% CI for estimates. 
Appendix Figure 5: Pre and post Medicaid expansion trends in DI recipients
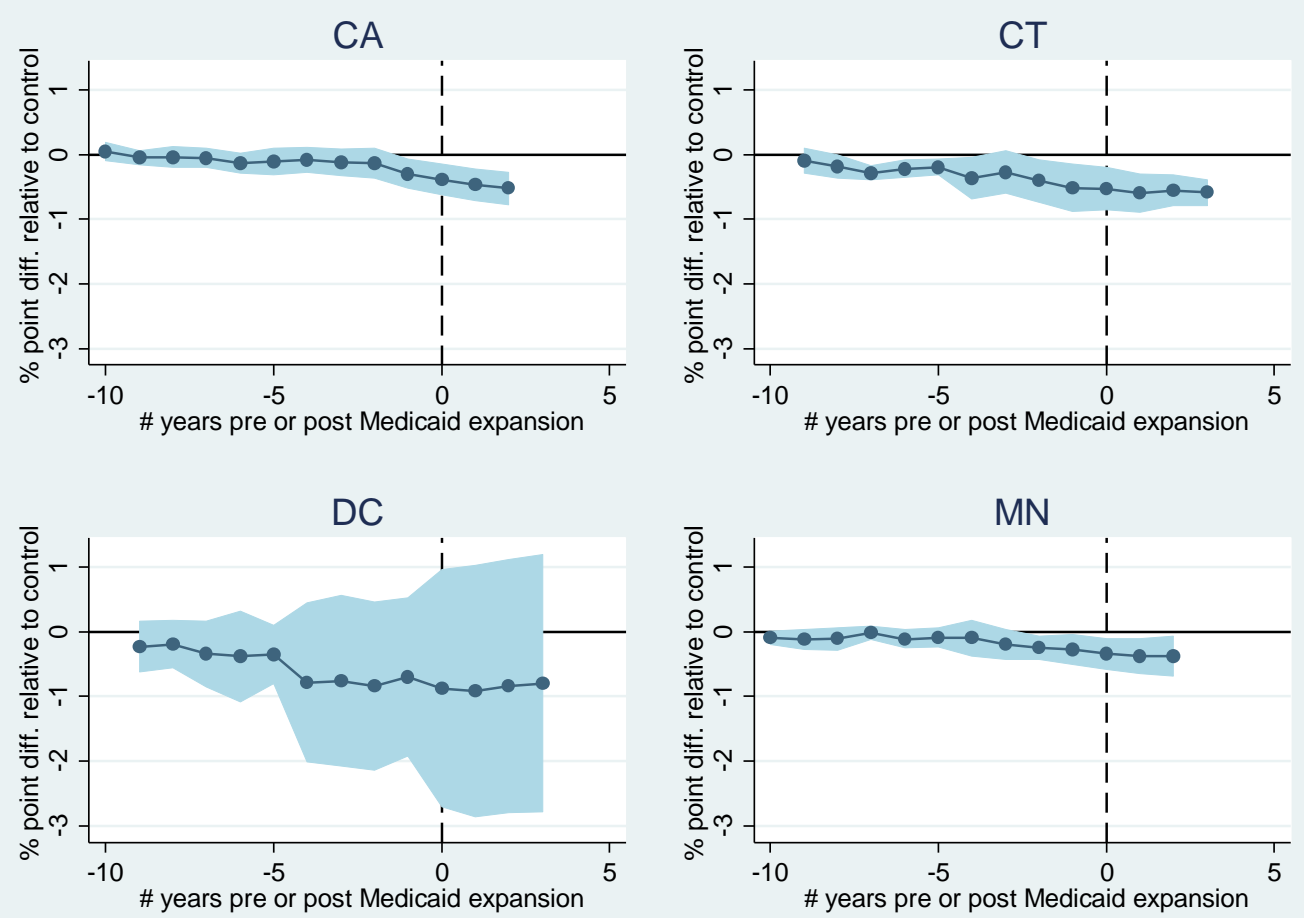

Notes: Figures generated using Equation 2 in text. Blue shading represents 95\% CI for estimates. 


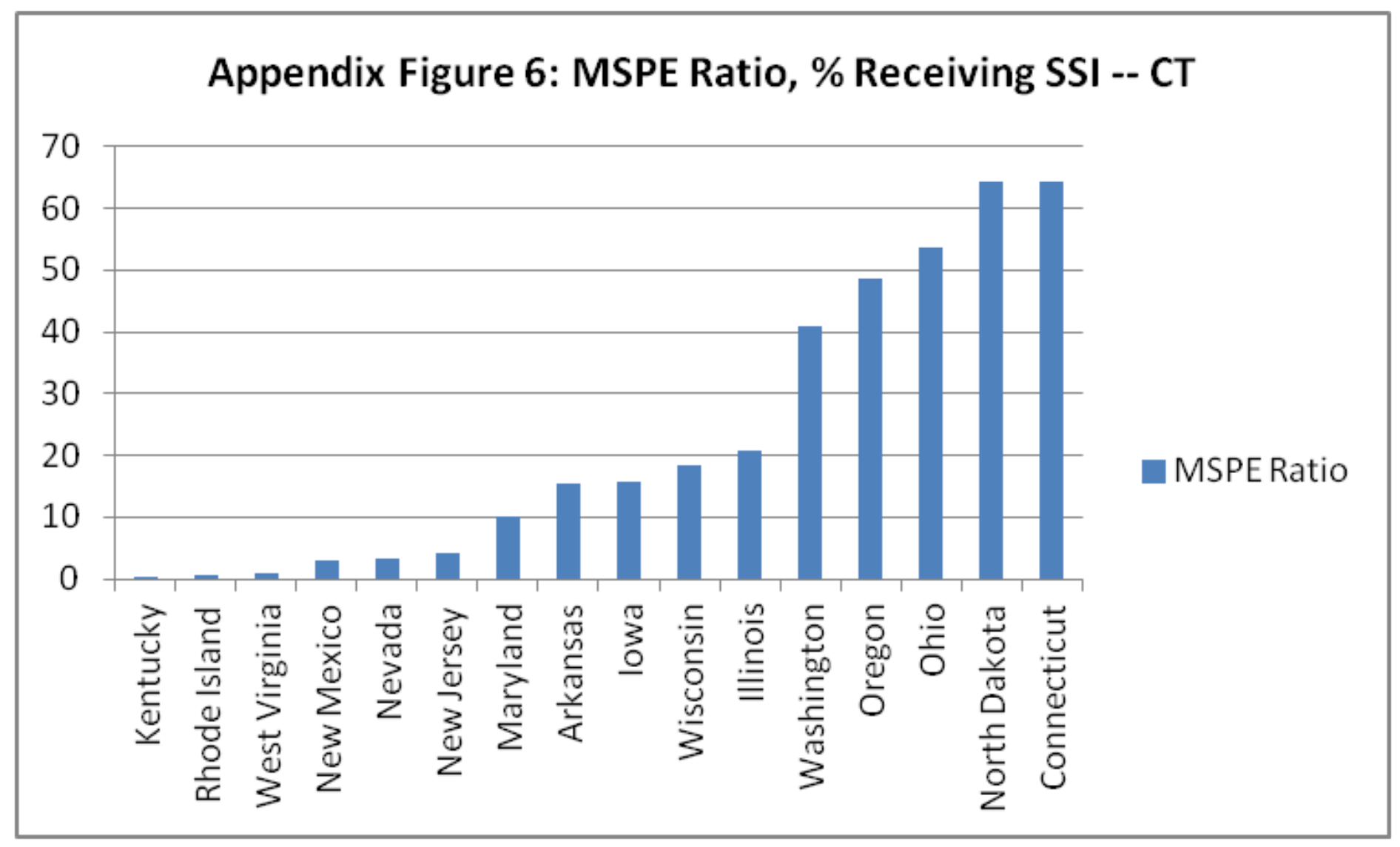

